\title{
Optimization methods applied to renewable and sustainable energy: A review
}

\author{
Ehsan Asadi and Seyed Jafar Sadjadi*
}

\begin{tabular}{|c|c|}
\hline CHRON I C LE & A B S T R A C T \\
\hline $\begin{array}{l}\text { Article history: } \\
\text { Received June 2, } 2016 \\
\text { Received in revised format June } \\
12,2016 \\
\text { Accepted June } 242016 \\
\text { Available online } \\
\text { June } 252016 \\
\text { Keywords: } \\
\text { Supply chain management } \\
\text { Biomass } \\
\text { Biofuel } \\
\text { BSC } \\
\text { Review }\end{array}$ & $\begin{array}{l}\text { Nowadays the use of fossil fuels as a non-renewable energy source has become a major } \\
\text { challenge because of the pollution and the environmental impact. Substitution of biomass as } \\
\text { an energy source and its supply chain design is the main question. Because of difficulties such } \\
\text { as supply chain complexity, uncertainty in variables and selecting the site of bio-refineries } \\
\text { many studies have been conducted in this regard. Studies in the field of biomass and biofuel } \\
\text { production are described and classified. Also the strategic decisions such as choosing the sites, } \\
\text { selecting energy conversation technology, ensuring economic, environmental, technical, and } \\
\text { social sustainability and tactical decisions including allocating resources to productive plants, } \\
\text { selecting transport modes, and types of warehouses are addressed in the reviewed papers. We } \\
\text { have reviewed } 140 \text { papers in the interval between } 1997 \text { and } 2016 \text { and classified them based on } \\
\text { the objective functions. The articles are classified based on their being single or multi } \\
\text { objectivity, linearity or nonlinearity. Finally, a classification based on the regions in which the } \\
\text { studies have been done. }\end{array}$ \\
\hline
\end{tabular}

\section{Introduction}

Nowadays the use of biomass as an environmentally friendly resource is very popular around the world such that it is estimated that this source contains 10-14\% of the world's energy resources (McKendry, 2002), because the use of biomass creates an energy production cycle without $\mathrm{CO}_{2}$ (Mohammed et al., 2011). There is a great tendency all over the world to replace fossil fuels with biomass to produce heat and electricity (Demirbas et al., 2009). According to the published statistics by BP ${ }^{1}$ based on the current global energy consumption the energy warehouse of oil and natural gas covers the next 51 and 56 years respectively. For distribution of final products of biological resources such as ethanol and aviation fuel, it should be noted that the warehouse duration of these materials in the reservoirs is not long. In many cases using these energies the production centers are at the shortest distance to consumption centers the most important reason of which, is the unstable condition of these produced materials (Tatsiopoulos and Tolis, 2003). Since biomass is considered as a versatile source of energy, due to its usage in fuel production it is predicted that bioenergy will play an important role in global energy supply (Rentizelas

\footnotetext{
${ }^{1}$. http://www.bp.com/statisticalreview

* Corresponding author Tel.: +982177240129

E-mail address: sjsadjadi@iust.ac.ir (S.J. Sadjadi)

(C) 2017 Growing Science Ltd. All rights reserved. doi: $10.5267 /$ j.uscm.2016.6.001
} 
et al., 2009a). However, the heat or electricity costs of production by biofuels of woods are less competitive when compared with other conventional sources. This is due to various wood properties such as low energy density, high humidity and uncertainty in the quality and its access. So far 4 generations of bio-energy have been proposed each of which has its own advantages and disadvantages (Liew et al., 2014). Fig. 1 shows the relationships between the various stages of production from source to destination. Partial biofuel production processes are very complex and delicate and this shows the importance of providing cost optimization models. Supply chain is considered as one of the most important approaches in the design, planning and management of biomass energies such that since the production, this type of energies has been considered as one of the most important elements to reduce the production costs. Gold (2011) believes that supply chain plays a vital role in bio-energy production process particularly biomass because the appropriate design of the network can reduce a lot of unnecessary and excessive logistics cost and improve the processes of production and distribution of this type of energy. Biomass supply chain management is the integrated management of bio-energy production from the cultivation of biomass materials to energy conversion facilities.

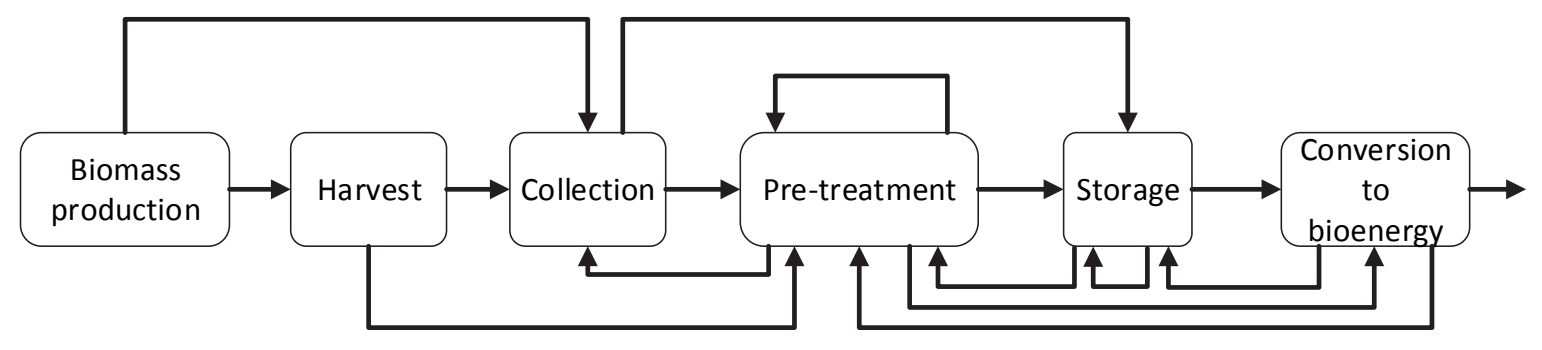

Fig. 1. Interrelationships and interdependencies of operations in the biomass supply chain (De Meyer et al. (2012))

\section{Review of modelling biomass supply chain}

The most important challenges that are associated with the supply chain of biomass materials include:

1. The extension of biomass supply centers: biomass agricultural land and farms are usually at distances from each other and their placement is usually sporadic (Marufuzzaman et al., 2014).

2. These materials usually have high volume and they are heterogeneous and light and to reduce their costs of transportation it is necessary to regulate them before transportation.

3. Warehouse time of fuel produced from this material: fuel produced from these materials cannot be preserved for a long time unlike fossil fuels and should be consumed in a short time (Ekşioğlu et al., 2009). The warehouse time of the biomass produced by these materials also depends on the type of feedstock used to produce fuel and some produced fuels can be preserved for a longer time.

4. Seasonality production of these cases: Biorefinereis to supply their feedstock need to bear in mind that these products are not harvested in all seasons. This issue leads to the cases such as proper warehouse centers for preservation at the time that these materials are not produced.

5. Deterioration property of these materials: considering the deterioration of the materials is one of the cases that should be considered in the inventory centers.

6. Appropriate transporting infrastructures: transporting these materials is usually through the road transport by truck that rail transport has also been taken into consideration recently.

Fig. 2 shows bio-product production processes. To face the challenges in designing biomass supply chains, models are developed. 


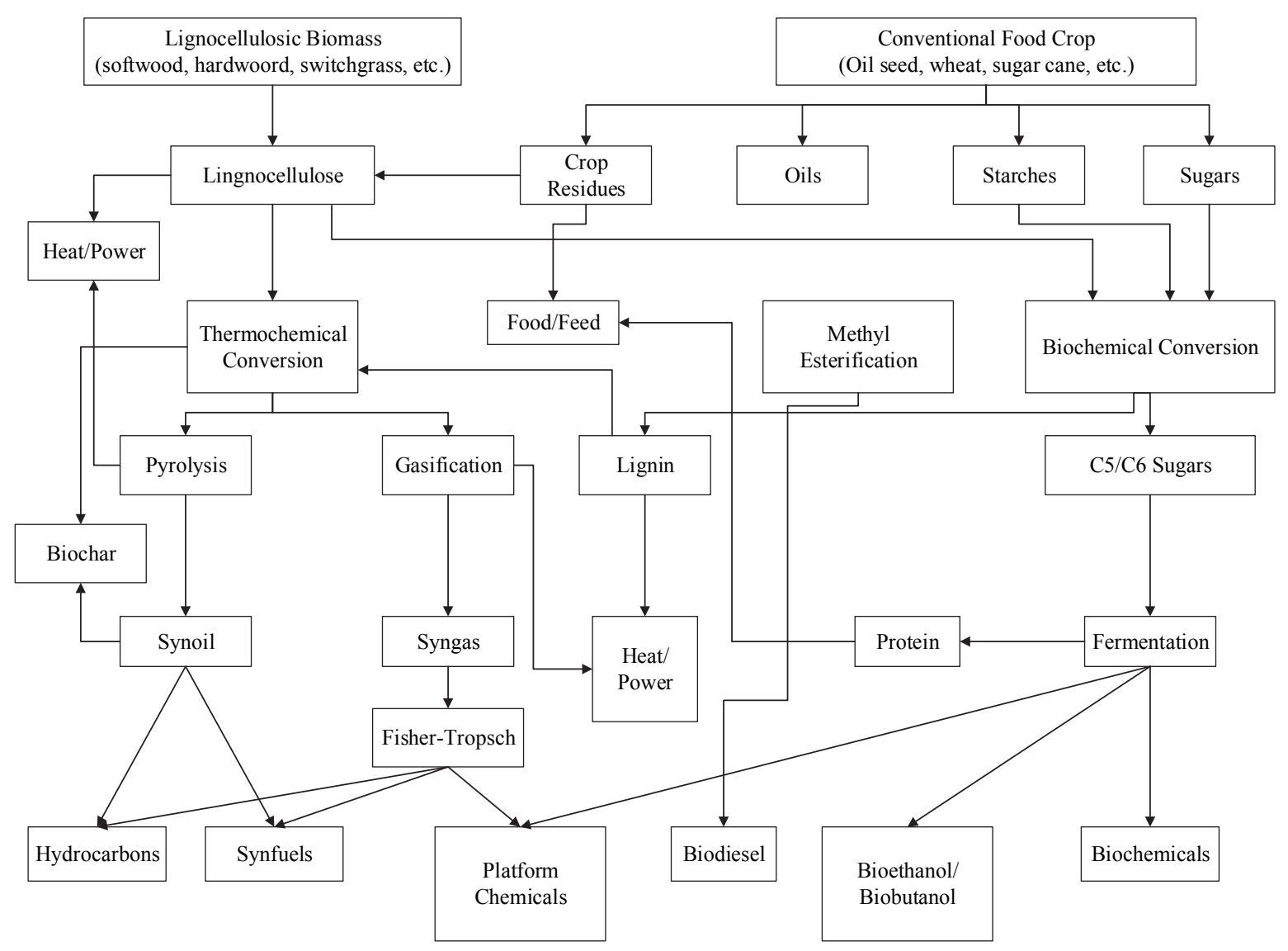

Fig. 2. Process of generating bio-product (Murphy et al. (2011))

\subsection{Single objective studies}

In this part, the single objective articles are categorized by the types of objective function. In order to facilitate the assessment of methods, they are classified based on three approaches. 1) LP 2) NLP 3) Other.

\subsubsection{LP models}

LP models include a wide range of papers. One of the first researches in the field of biomass supply chain was conducted by Cundiff et al. (1997) that through presenting ILP model analyzed biomass transporting costs from harvesting to the refinery and by site selection of the refineries the costs associated with biomass supply chain were improved. Nagel (2000) developed a linear programming method in which it was attempted to find the most economical biomass supply chain structure. The model that he presented was related to three different types of operational companies. Through defining various scenarios and sensitivity analysis, he analyzed the impact of various factors on the model. His model is capable of determining the optimum location, capacity, and technology. Tembo et al. (2003) presented a multi-region, multi-period linear model in which the amount of feedstock production, delivery, and production processes of lignocellulos biomass are determined. Their model offers cost effective reduction opportunities and presents answers to questions in relation to timing of harvest and storage, inventory management, bio-refinery size, and bio-refinery location. They finally examined changes in the rate of return and lifetime of the project. Tatsiopoulos and Tolis (2003) provided a model that simulates cotton-stalk supply chain. Their model while feasibility and assessment of the problems related to integrated logistics networks, optimizes transportation costs. They addressed other economic aspects of the logistics processes such as collection and warehouse. In order to find optimal locations of the warehouses, GIS is used in the paper. 
Freppaz et al. (2004) to make decisions on the economic evaluation of biomass to generate electricity in a specified region, a mathematical model was combined with GIS by a DSS (decision support systems). Their model selected the location of plants, their optimal size, the energy peculiar to each region, and how to collect and cultivate biomass while taking into account the economic, technical, regulatory, and social aspects in each region. Gunnarsson et al. (2004) decided about the time and placement of converting forest residues and how to transport them to the factory. Considering the course of a year they began modeling. In order to solve their model they acted in two ways: 1) CPLEX software, 2) heuristic method. Dunnett et al. (2007) proposed a model to determine biomass to heat supply chain. Their model, which was 12 -month period, optimizes the supply chain's operational schedule. They performed a comparison between their model and presented heuristic models by sensitivity analysis. Leduc et al. (2008) proposed a MILP model to determine the optimal location and size of methanol and gas manufacturing plants. Their model starts with supply of biomass to the biofuel production and its sales. They presented three scenarios related to the optimum location of methanol production plants in Austria.

Ekşioğlu et al. (2009) analyzed logistical problems associated with the biomass to bio-refinery supply chains. Their model creates a harmony in long-term decision-making in the supply chain and shortterm decisions in logistics. Their model determines the size and location of the bio-refineries. Also the breakdowns, seasonal biomass supply, and supply availability are considered. Kanzian et al. (2009) designed and tested four different scenarios for biomass supply. The developed scenarios use a GIS system and linear programming. The results indicated that direct transport of solid fuel wood as round wood and chipping at the plant is the cheapest supply system and using harvesting residues can only be recommended for large plants due to poor fuel quality. Xie et al. (2009) made decisions about the site selection of bio-refineries by providing a MILP model using GIS. They also proposed a prototype to guide future research on site selection and cost analysis in the field of biomass. Leduc et al. (2010a) proposed a dynamic MILP model to find the best place for methanol plant and minimize production costs. They studied three factories with capacities of 100, 200, and $400 \mathrm{MW}$. The production of lignocellulosic based methanol via gasification has been studied. Leduc et al. (2010b) proposed a MILP model to determine the optimal location for ethanol production plants with the aim of minimizing the costs of production. The purpose of Lambert and Middleton (2010)'s article is to assess the effectiveness of field-to-refinery and finding the optimal biomass harvest, storage, transportation, pretreatment, and refining activities.

Parker et al. (2010) represented a bio-refinery sitting and resource assessment optimization model. They used a MILP model and different types of biomass to maximize profits in the biomass supply chain until bringing it to fuel terminals. The presented sensitivity analyses examine the effects of changes in policies and technologies. Huang et al. (2010) proposed a multi-period MILP model to make strategic decisions in the supply chain of biofuel. They minimized supply chain costs from farms to final consumer during a specified time horizon. In their case study they studied 8 biomass supplies and achieved the lowest cost by an intelligent system. Čuček et al. (2010) based on a MILP model, proposed a method for the synthesis of regional renewably energy supply chain. Their method responds to the challenges of distribution and diversity in space and time. A four-layer supply chain including harvesting, preparation, core processing, and distribution of products is provided. Van Dyken et al. (2010) provided a MILP model to model key component of biomass supply chain including supply, processing, storage and demand of different types of biomass. Their model is formed of two LP-MIP parts for operational model and Dynamic Programming for the investment. They developed eTransport model used for modeling energy systems with multiple energy transportation, by adding nodes to consider changes in moisture content and its effects on other properties of biomass.

Lam et al. (2011) using model-size reduction techniques modeled supply networks and production of large-scale renewable energies. Using the four-layer model previously raised by Čuček et al. (2010) and applying three techniques including 1) reducing the connectivity, 2) eliminating unnecessary variables and constraint, and 3) merging the collection centers, they developed a model. Leão et al. 
(2011) to model the bio-diesel supply chain with family farm source and considering the agricultural, logistic, industrial, and social aspects, they proposed the optimization model. Their model which is based on a planning horizon, identifies the quantity, location, technology, and capacity. An et al. (2011) while minimizing the profit, searches to find the locations of the facilities, capacities, technologies, and material flow in the lignocellulosic biofuel supply chain. To this end, they presented a time-stage, multicommodity, and production/distribution system model. Kocoloski et al. (2011) presented a model for the single and multi state regions that while minimizing the cost, to locate ethanol production refineries deals with communication between the demands and the refineries. Kim et al. (2011a) by providing a MILP model presented the optimum number, locations, and sizes of manufacturers of different biofuels. They also made decisions to transport of biomass, intermediate product, and final product from supply sectors to the conversion plants and from conversion plants to the final market. Kim et al. (2011b) improved the model proposed by Kim et al. (2011a) through considering the uncertainties. They firstly improved the proposed model by maximizing the profit and through a scenario and then determined the objective function value by analyzing 14 parameters obtained by their single scenario model.

Papapostolou et al. (2011) proposed a mathematical model to model supply chain of the biofuel through considering both technical and economic parameters that affect the supply chain. Their point of view can solve a wide range of issues with different dimensions. The business policies have been also considered in their perspective. Zhu et al. (2011) proposed a model to investigate and solve dedicatedbiomass supply chain problems including low bulk density, restrictions on harvesting season and frequency, content variation with time and circumambient conditions, weather effects, and scattered distribution over a wide geographical area. The model includes harvesting switchgrass area to biorefinery. Elia et al. (2011) proposed a MILP model for hybrid coal, biomass, and natural gas to liquids (CBNTL) supply chain network. Their model minimized the production costs by site selecting of CBNTL's facilities, combining feedstock, and size of facilities. Marvin et al. (2012) produced ethanol by providing MILP model in biochemical technology and the conversion of five types of agricultural biomass such as barley, corn, oats, spring wheat (including durum), and winter wheat. The optimal location and capacities of refineries were determined and sensitivity analysis in relation to price uncertainty was also provided by them. A multi-period MILP model was presented to design and plan the biofuel supply chain in Argentina, by Andersen et al. (2012), including all components of the supply chain including crop fields, storage and production plants as well as distribution centers for internal and external markets. The seven-year time horizon with 48 time period is considered in the models.

Keirstead et al. (2012) presented an integrated resource modelling framework which determines an optimized low-cost energy supply system including the choice of conversion technologies, fuel sources, and distribution networks. Mansoornejad et al. (2013) using two types of scenarios that were called market scenario and supply chain network, proposed a model for forest bio-refinery delivered. First the supply chain network alternatives were identified and evaluated in terms of usefulness (profitability, flexibility, and robustness) and then a multi-echelon multi product MILP model was proposed. Zhang and $\mathrm{Hu}$ (2013) proposed a MILP model in the biofuel supply chain. Their multi-period models determine biofuel supply chain facility location, facility capacity at strategic levels, and biofuel production decisions at operational levels. They also coordinate between the suppliers and demanders by considering shortage penalty and storage cost. Ghaffariyan et al. (2013) in their model by considering five operational factors such as energy demand, moisture mass fraction, interest rate, transport distance, and truck payload, minimized the costs. The supply chain model is formed of the levels of extraction feedstock from harvesting sites, storage at roadside, chipping the materials, and transportation the chips to plants.

Awudu and Zhang (2013) offered a stochastic LP model. Their single-period model while maximizing the profit, determines the amount of purchased and consumed biomass. They solved their model by benders decomposition and Monte Carlo simulation technique and in order to compare its performance, they compared the model with simulation methods. Osmani and Zhang (2013) proposed a two-stage stochastic MILP model to minimize profit. Their multi-feedstock model addresses the strategic 
decisions such as location, production capacity, and allocation in the first phase and tactical decisions are made in the second phase. They compared the results with certain models. Zhang et al. (2013) proposed an integrated MILP model to make optimal decisions regarding the lignocellulosic-based (switchgrass and crop residue) bioethanol supply chain. Their model determines the level of inventory, selection of biomass, and production volume of bioethanol cultivation site. Ebadian et al. (2013) determined a methodology by combining the MILP and simulation to design agricultural biomass supply chain. After designing the supply chain, operational decisions such as the number of machines required for each operation, scheduling of daily working, utilization rates, and storage capacities are made.

Sharma et al. (2013) conducted biomass supply chain modeling considering different scenarios and uncertainty in climate conditions. Based on 1 year time horizon, they determined the strategic, tactical, and operational decisions while minimizing the costs. Foo et al. (2013) by providing a robust LP model they minimized the devastating ecological effects of the supply chain. Then through developing their model they created a MILP model and measured its flexibility by different scenarios such as anticipated closure or expansion of mills. Omu et al. (2013) proposed a MILP model to technology selection, unit sizing, unit location, distribution network structure to minimize annual investment and operational costs. Lin et al. (2014) proposed a MILP model to optimize strategic level such as numbers, locations and capacities of facilities, and biomass and ethanol distribution patterns and technical decisions such as biomass production delivery, operating schedules, and inventory monitoring. Their model includes different parts of the supply chain including harvesting, packing, in-field transportation, stacking, transportation, preprocessing, and storage to produce and supply ethanol.

Roni et al. (2014) proposed a MILP model to model supply chain of hub-and-spoke for long-haul delivery of biomass. Their model, which is solved by benders decomposition algorithm, minimizes the costs of delivery. To model the short and long distance deliveries, trucks and trains were used respectively. Xie et al. (2014) proposed a multistage MILP model that integrates multimodal transportation including truck, single rail car, and unit train and minimized infrastructure, feedstock harvesting, biofuel production, and transportation costs. They also considered the locations and capacities of transshipment hubs, bio-refineries, and terminals are determined for seasonal biomass feedstock and biofuel demand. Pantaleo et al. (2014) to optimize strategic design of multi-biomass and natural gas supply chain presented a MILP model in urban areas. The model is including spatial and temporal allocation of biomass supply, storage, processing, transport, and energy conversion. The aim of which is representing the relationships between the biomass processing and biofuel energy conversion steps, and on the trade-offs between centralized district heating plants and local heat generation systems.

Grigoroudis et al. (2014) used a MILP model to select the installed facilities based on the minimum cost and maximum performance and presented its output as the input of a RDEA (recursive DEA) model to design a supply chain network. Paulo et al. (2014) designed a supply chain network that using the economic and environmental solutions enhances energy efficiency. The model can determine storage and energy facility locations including production technologies to install in each location, flows of biomass and energy products, and transportation modes for biomass and the products to determine the maximum net energy production. Marufuzzaman et al. (2014) presented a multi-modal transportation model in which intermodal hubs are subject to site-dependent probabilistic disruptions. Probability distribution of the intermodal hubs is estimated by a model of real-world data. A Benders decomposition algorithm is used to solve this problem. Their model determines not only the optimal intermodal hub locations and shipment routes for delivering biomass in order to optimize system's performance under normal conditions, but also there are losses when intermodal hubs are disrupted due to natural disasters such as flooding, hurricane, and draught.

Balaman and Selim (2014a) developed a supply chain network design to produce biogas through anaerobic digestion of biomass. With a MILP model after determining the number, capacity and 
optimal locations of the biogas plants and warehouses, they determined the biomass supply and made decisions to distribute products. Tong et al. (2014) proposed a multi-period fuzzy MILP model to optimize the supply chain design, insertion point selection, and production planning and provided a fuzzy model due to determine the biomass availability and product demand and uncertainties contained in them. Other factors such as diverse conversion pathway, technology, insertion point selections, biomass seasonality, geographical diversity, biomass degradation, demand distribution, and government incentives are considered in their model. Ahn et al. (2015) proposed a model for strategic planning in relation to designing the biomass to biofuel supply chain from fields to costumers. For this purpose they offered a MILP model which is different from the previous models in converting the microalgae to biofuel. In their model the producing of raw materials as $\mathrm{H} 2 \mathrm{O}, \mathrm{CO}_{2}$ and purchasing other raw materials is considered. Due to the consideration of changes in demand, they analyzed their model under two multi period and single period states.

Gonela et al. (2015) by simultaneous consideration of two models of food based and lignocellulosic based to produce biofuels, proposed a stochastic model. They examined different type of bioethanol plant configurations in order to meet high sustainability standards and design robust and sustainable industrial symbiosis based hybrid generation bioethanol supply chains. In their model environmental factors such as greenhouse gas (GHG) emissions, irrigation land and water usage, and energy efficiency are considered. Sharifzadeh et al. (2015) modeled decision-making in relation to the three areas of centralized, decentralized, remote production, considering different costs of production and transportation. In their paper, they analyzed two different types of supplier. The first supplier has economic price at high-volumes and the second supplier has lower cost at lower-volumes but farther and scattered distance. They proposed a two-stage stochastic model in the field of pyrolysis.

Paulo et al. (2015) modeled the supply chain of the forest residues to produce bio-energy and considered three levels on the supply chain such as biomass sites, electricity production facilities, and demand centers. Their model while minimizing the transportation costs variability, fixed operating costs, and investment costs, determined the optimal level of transportation and biomass allocation. Li and Cremaschi (2015) modeled all processes in the production to consumption, such as the biomass growth and its planting-campaign schedule, the location and the capacities of the bio-refineries, and the transportation cost from the planting regions to bio-refinery locations, and from bio-refinery locations to demand centers. They assumed the costs on a yearly-basis. Wu et al. (2015) proposed a stochastic model to model under uncertainty including uncertainty in interval values and probability distribution in multistage background. Interval-based solutions are risky and choosing between levels of price that optimizes the risk at the same time is controversial. They proposed MSICCP (Multistage stochastic inexact chance-constraint programming) by combining inexact chance-constraint programming and multistage stochastic programming.

Sosa et al. (2015a) analyzed the moisture content and its effect on the cultivation of two types of short wood and whole trees biomasses. In order to transport the needed feedstock, they used two different types of trucks ( 5 axle \& 6 axle). They presented three scenarios to assess their model. In scenario 1 the power plant accepts material at any moisture content percentage. In scenario 2 the material must meet a moisture content range between $30 \%$ and $45 \%$. In scenario 3 the material must meet a moisture content range between $30 \%$ and $40 \%$. Sosa et al. (2015b) analyzed wood biomass and its competitive advantages with other wood-based industries. Considering the moisture content, weight, and energy content of biomass materials, and using drying curves in 2-year period, they performed modeling. Given harvesting, chipping, storage, and transportation costs, they attempted to minimize the expenses. The considered means of transportation is truck. At the end, they analyzed their model by 5 scenarios. In an article based on the land use restriction approach, Bai et al. (2016) presented two models with land constraints and cap-and-trade mechanisms based on the supply chain of competitive biofuel production. They performed sensitivity analysis on their models that were solved by GNG (Generalized Nash Equilibrium) and KKT (Karush-Kuhn-Tucker) methods. Shabani and Sowlati (2016) modeled the uncertainty in 'biomass quality', including moisture content and higher heating value, and 'monthly 
available biomasses' from different suppliers with regard to annual periods. In order to analyze modeling the uncertainties, they proposed a stochastic-robust model and by providing various scenarios they attempted to find acceptable quality at the highest profit level possible. Lim and Lam (2016) proposed a LCA viewpoint to solve existing problems in the choosing of biomass feedstock. By classifying the feedstock based on its constituent materials (rather than the species) presented a new classification called BELCA (Biomass Element Life Cycle Analysis). Their analysis allows to use alternative materials with the same essential features when the required feedstock is not available. Zhang et al. (2016a) proposed a multi-stage MIP model through considering two transportation methods of truck and rail to minimize supply chain costs including infrastructure, feedstock procurement harvest, transport, storage, and process. The model determines number, capacity, and location of storage yards and bio-refineries as strategic decisions while it shows tactical decisions included the amount of biomass shipped, processed and inventoried during a time period. Duarte et al. (2016) proposed a mathematical model including economic and environmental issues. They considered coffee cut stem for producing bioethanol. The MILP model that considers GHG emissions, is multiperiod. Woo et al. (2016) proposed a MILP model that minimizes costs annually. Their model determines the optimal design of the supply chain and main cost-drivers, manage logistics operations, and make strategic decisions such as capital investment and energy import planning. Zhang et al. (2016b) by providing an integrated approach by combining GIS and simulation and optimization methods determined the facility locations as simulation model input to minimize the costs. Using the inventory control models they attempted to minimize the costs and energy consumption and the emitted GHG.

\subsubsection{NLP models}

The true nature of the supply chain sometimes requires the NLP approach for modeling. However, these models are more complex in modeling. Krukanont and Prasertsan (2004) with a focus on rubber trees, proposed a model to determine the highest cost payable in addition to determine the optimal capacity of the plants in a particular area. Their mathematical model was presented in combination with a simulation model in which GIS was used to find suitable locations for the plants. López et al. (2008) created a Particle Swarm Optimization (PSO) algorithm to solve the nonlinear model for determining NPV, the optimal location, and biomass supply area. They performed optimization through considering three types of technology. Their PSO algorithm included 15 and 50 particle in the swarm. In order to evaluate their answers they compared their model with a genetic algorithm.

Bruglieri and Liberti (2008) proposed mathematical models to solve problems created by planning and running energy production processes arising from burning biomass. Their model seeks to find the answer to questions such as purchase or production, how to carry materials to plants, and plants locations. To solve two nonlinear models provided by them, the spatial branch \& bound approach is applied. Izquierdo et al. (2008) proposed a PSO model to optimize flow in biomass supply chain. Using their model in biomass supply chain strategic planning, they presented various functions. By introducing discrete integer variables in their non-linear programming, they chose the type of technology. Frombo et al. (2009) proposed a GIS-based EDSS (environmental DSS) model that models energy production from forest biomass. Their model, which is a long-term model, includes the decision variables associated with the location of plants, conversion process (pyrolysis, gasification, combustion), and harvested biomass. Their nonlinear model includes environmental restrictions in the real world.

Rentizelas et al. (2009b) presented a DSS model based on an NLP model to design a system based on the use of tri-generation (electricity, heating, cooling) biomass supply chains. With the purpose of increasing the investment profits, they developed a model including multi-biomass supply chain, the energy conversion facility, and district heating \& cooling network. A hybrid optimization method is employed for the system-wide optimization to overcome the limitations introduced by the combination of analytical logistics modelling and system-wide optimization. Rentizelas and Tatsiopoulos (2010) 
presented a hybrid optimization approach to solve nonlinear models for finding the best locations for a bioenergy facility. Their model focuses on minimizing investment and operational costs. In order to evaluate their model they compared it with the solution by two algorithms GA (stochastic) and SQP (exact optimization method). Velazquez-Marti and Fernandez-Gonzalez (2010) proposed a mathematical model to select the actual point on the GIS maps. The model groups the cities and finds a plant for them by the location and facilities' data and taking into account two criteria: 1) All produced energy must be consumed and 2) the costs of energy transportation must be minimized. Vera et al. (2010) provides the optimum profit by a BHBF (Binary honey bee foraging) algorithm. Their model presents the optimal locations, biomass supply area, and power plant size.

Gan and Smith (2011) presented a model that while minimizing the cost, determines the optimal size of plant and biomass area size and analyzed the effects of different factors on the size of the plant, supply area and cost. Bai et al. (2011) created a MINLP to determine the optimal number and location of the refineries. Using a langrangian relaxation based heuristic algorithm and branch \& bound they allocated biofuels demand and selected the route. Corsano et al. (2011) by providing a MINLP optimization model and sustainable design to behavior analysis of sugar/ethanol supply chain, they combined supply chain design with the design of the ethanol production plant. Their model besides the optimal transportation, determines the location and capacity of plants and warehouses. Zhang et al. (2011) presented a two-stage method to identify the best locations for producing biofuel (first-stage). They first introduced optimum sites for construction of facilities by GIS and then using the listed places minimized the costs (second-stage).

Singh et al. (2011) using GIS and NLP evaluated the feasibility of building plants and their optimization. GIS is used to determine the distribution of crop residue and NLP is used to select the suitable size for the plants. Sultana and Kumar (2011) minimized the costs through the study of the combination of different types of lingocellulistic biomass, like agricultural and woody biomass. Three types of biomass including wheat straw, corn stover, and forest biomass in different forms, loose biomass, bales/ bundles, chopped/chipped, and pellets, are discussed by them. Leboreiro and Hilaly (2011) presented a model based on a non-dimensional transportation factor for evaluating economic aspects of biomass collection, transportation and storage. They analyzed farm-to-plant and farm-tostorage transportation and production costs.

Yagi and Nakata (2011) evaluated the economic feasibility with regard to forest biomass and site selection, size and optimum number of factories, and production costs based on the data provided in relation to the distribution of resources and the merit function. Sultana and Kumar (2012) offered a methodology for spatial analysis by combining GIS and AHP to find the optimum location of biomass based facilities. Using a location-allocation model while selecting the location of the facilities, they minimized the costs. Their model also includes the environmental factors such as flood plains, conservation areas, and habitat sites. Chen and Fan (2012) offered a MISP model for strategic planning of the supply chain systems and optimal resource allocation in an environment of uncertainty. For this purpose, a two-stage stochastic model and lagrangian relaxation approach were developed to find the optimal location and size of refineries and terminals, feedstock procurement plans, and ethanol production and distribution plans. Avami (2012) presented a model that links the agriculture and industry sectors. She proposed an optimal economic supply chain by considering the technical and agricultural aspects. Her model integrates different components of the biomass supply chain. Avami (2013) developed her previous model, Avami (2012), through considering all bioethanol technologies. She developed a model based on 4 scenarios in relation to biomass first and second generation. Leboreiro and Hilaly (2013) through combining different stage of biomass supply such as collection, transportation, and storage, they proposed a model that determines the optimal capacity of the plant. Their model focuses on minimizing transportation and collection costs.

Shabani and Sowlati (2013) by providing a MILP model and considering tactical decisions such as biomass procurement, storage, energy production, and ash management, while studying different 
scenarios, they performed modeling and improved environmental impacts of the plants based on ash recovery system. Gómez-González et al. (2013) introduced a hybrid method using a PSO algorithm to find the location and size of biomass fuelled gas micro-turbine plants. Their model considers local distribution of biomass resources, biomass transportation and extraction costs, operation and maintenance costs, power losses costs, network operation costs, and technical constraints. While providing an algorithm called JFPSO, they compared that with other existing algorithms. Rentizelas et al. (2014) determined the location capacity, biomass procurement, and biomass inventory while considering and comparing the two structures BSC a pellet production system and a centralized CHP (Combined Heat and Power) unit.

Geraili et al. (2014) using an iterative strategy integrates the Net Present Value optimization with detailed mechanistic modeling, simulation, and process optimization. They solved their 3-step model, which was consisted of strategic optimization, process modeling simulation, and operational optimization, by a meta-heuristic algorithm. Poudel et al. (2016) proposed a pre-disaster model that strengthens supply chain of biofuel after the disaster's occurrence. The model was solved by Benders decomposition algorithm because of the NP-hardness of it. The statistical results showed that the cost of producing a gallon of biodiesel under disaster situation is $0.4 \$$ higher than the normal conditions that this value is reduced to $0.27 \$$ in their model. Using a probabilistic variable $\left(q_{j k}\right)$, they entered rate of damage after the disaster. Given that the cost of transporting biomass from agricultural lands to the relevant facilities is a key element in the cost of production of biofuels, Golecha and Gan (2016a) proposed a model that unlike other articles which consider the costs linearly by adding the spaces, they consider the costs variable by adding the spaces with a radius of distance from the points. For this purpose, they used an Amplification Factor $(\psi)$. Then based on the provided model, they analyzed the numerical data. Foe any radius of the original point of agricultural land, they offered a general formula. After dividing the larger sections into smaller parts, the movement radius was obtained by integrating the distance of smaller parts. de Andrade et al. (2016) aimed to calculate the average flow rate in relation to the microalgal biomass production in outdoor tubular photobioreactors that addresses maximum biomass production in a specified time period. In order to show the results of two strategies i) an optimal and (ii) a near-optimal that have non-linear objective functions, the simulation is used.

\subsubsection{Other methods}

In this section another part of the papers that include the game theory, decision making and other approaches that exist in the field of modeling are divided. Gronalt and Rauch (2007) proposed an approach to design wood biomass network in a specified area. Their network includes extensive network of forest areas and large plants. They evaluated their model by calculating the cost of system for various supply lines. Walla and Schneeberger (2008) assessed electricity and biogas production costs and their relation to the size of their plants. Then they developed a model that resulted in the curves of costs of electricity production and the transportation costs of maize silage and biogas slurry. Their model specifies the most economic size of the plant. Reche-López et al. (2009) presented a paper to optimize the location and area of the supply chain using four meta-heuristic methods. Accordingly they proposed two Simulated Annealing and Tabu Search (trajectory) and two GA and PSO (population-based) methods. After the analysis of these methods, they proposed a new PSO algorithm and analyzed the results of their models.

Ebadian et al. (2011) proposed an IBSAL (Integrated Biomass Supply Analysis and Logistics) based stochastic simulation and using their model called IBSAL-MC (Multi Crop), considering the uncertain weather conditions and timing of planting and profit simulated the supply chain from harvesting and collecting to end user. IBSAL-MC is a hybrid push-pull model. Bai et al. (2012) considered a noncooperative bi-level Stackelberg leader-follower game model with a cooperative game mode. The game-theoretic model determines the number, location, and size of the refineries and the cost of feedstock through considering the farmer and manufacturer's decisions simultaneously. Clancy et al. (2012) presented a stochastic budgeting model to simulate the NPV of different biomass investments. 
By studying on the willow and miscanthus as feedstock, they compared the NPV model with models of Cumulative Distribution Functions (CDFs) and Stochastic Efficiency with Respect to a Function (SERF). Wang et al. (2013) using the game theories, they analyzed the effect of RIN system on the stakeholders' decision such as farm land use, bio-refinery investment, and biofuel production. The Renewable Identification Number (RIN) system is a tracking mechanism that enforces the U.S. Renewable Fuel Standard by monitoring obligated parties' compliance with the biofuel consumption mandates. Liu et al. (2015) performed risk assessments in biofuel refineries in China. They studied various risks including market risk, production risk, technology risk, economic risk, and management risk in the upstream, midstream, and downstream of the biomass supply chain. Holmgren et al. (2015) studied greenhouse gas emissions, feedstock, heat and $\mathrm{CO}_{2}$ in the bio-SNG process by an LCA viewpoint and provided a model to measure GHG. San Miguel et al. (2015) considering two harvesting technologies (bale harvesting vs. chip harvesting), including a sensitivity analysis on the effect of transportation distance (from 10 to $100 \mathrm{~km}$ ), the environmental and energy performance of the experimental biomass supply chain and the economic viability of the bioenergy system in its different scenarios. They investigated based on Life Cycle Analysis (LCA) methodology.

Zamar et al. (2015) dealt with uncertainties in biomass forest feedstock with the development of a model. They proposed their model by a QUANTILE-based scenario Analysis (QSA) approach. Jin and Illukpitiya (2016) due to major costs of raw material production such as harvest, transportation and storage costs, they minimized these costs in the real world. In addition they attempted to estimate the cost by providing a model under all harvest programs. Then they proposed a model for harvesting and hauling costs. Their model considers different costs such as fuel consumption, ownership costs, repair cost, diesel fuel cost, lubrication cost, and harvesting cost. The model is solved under three 3-month, 6-month, and one-year scenarios and their results are presented. Golecha and Gan (2016b) analyzed the effect of annual changes in the amount of corn that is between $20-30 \%$ per annum. In order to present the impact of these changes, they used the game theory based on Pareto optimal solution. They analyzed the effects under three conditions 1) Balanced market, under oligopolistic-oligopsonistic equilibrium pricing 2) Bio-refineries maintain a supply region, based on average yield density 3) Bio-refineries maintain a supply region, based on "Derisked" yield density. Chai and Saffron (2016) considered 3 scenarios with regard to storage capacity and the amount of biomass moisture content in order to produce woody biomass-based biofuel. Their model minimizes the costs and determines the amount of moisture and biomass optimal warehouse size. They performed sensitivity analysis under three scenarios and discussed the difference among three scenarios in terms of on-site drying and hauling, drying, torrefaction (a biomass upgrading technology), grinding, and pelletization. The reviewed studies are summarized in Table 1, including LP, NLP, and other methods.

Table 1

Single objective models

\begin{tabular}{lllllll}
\hline Author(s) & Design & Object & Object detail & GIS & Case & Detail \\
\hline Cundiff et al. (1997) & LP & Economic & Cost & no & Italy & Piedmont \\
\hline Nagel (2000) & MILP & Economic & Cost & no & - & - \\
\hline Tembo et al. (2003) & MILP & Economic & NPV & no & USA & Oklohama \\
\hline Tatsiopoulos and & LP & Economic & Cost & yes & - & - \\
\hline Freppaz et al. (2004) & MILP & Economic & NPV & yes & Italy & Val Bormida/Savona \\
Krukanont and & NLP & Economic & Cost & yes & Thailand & southern \\
Gunnarsson et al. & MILP & Economic & Cost & no & Sweden & north \\
\hline Dunnett et al. (2007) & MILP & Economic & Cost & no & - & - \\
Gronalt and Rauch & Network & - & - & no & - & - \\
Leduc et al. (2008) & MILP & Economic & Cost & no & Austria & - \\
López et al. (2008) & NLP & Economic & Profitability & yes & - & - \\
Walla and & Other & - & - & no & & - \\
Bruglieri and Liberti & MINLP & Economic & Cost & no & Italy & - \\
Izquierdo et al. & NLP & Economic & Cost & no & Italy & Val Bormida/Savona \\
Ekşioğlu et al. (2009) & MILP & Economic & Cost & no & USA & Mississippi \\
\hline Frombo et al. (2009) & MINLP & Economic & Cost & yes & Italy & Val Bormida/Savona
\end{tabular}




\begin{tabular}{|c|c|c|c|c|c|c|c|}
\hline Author(s) & Design & Object & Object detail & GIS & Case & Detail & \\
\hline Rentizelas et al. & NLP & Economic & NPV & yes & Greece & Thessaly & \\
\hline Reche-López et al. & Heuristic & Economic & Profitability & yes & & & - \\
\hline Kanzian et al. (2009) & MILP & Economic & Cost & yes & Austria & - & \\
\hline Xie et al. (2009) & MILP & Economic & Cost & yes & USA & South Carolina & \\
\hline Leduc et al. (2010a) & MILP & Economic & Cost & no & Sweden & Northern & \\
\hline Leduc et al. (2010b) & MILP & Economic & Cost & no & Sweden & Northern & \\
\hline Lambert and & MILP & Economic & Profit & no & USA & North Dakota & \\
\hline Parker et al. (2010) & MILP & Economic & Profit & yes & USA & Western USA (Texas, & \\
\hline Huang et al. (2010) & MILP & Economic & Cost & yes & USA & California & \\
\hline Čuček et al. (2010) & MILP & Economic & Profit & no & Central & & - \\
\hline Van Dyken et al. & MILP (Dynamic & Economic & Cost & no & - & & - \\
\hline Rentizelas and & NLP,Heuristic & Economic & NPV & no & Greece & Thessaly & \\
\hline Velazquez-Marti and & NLP & Economic & Cost & yes & Spain & Valenciana & \\
\hline Vera et al. (2010) & NLP,Heuristic & Economic & Profit & yes & Spain & Úbeda/Jaén/Andalusia & \\
\hline Lam et al. (2011) & MILP & Economic & Profit & no & Slovenia & & - \\
\hline Leão et al. (2011) & LP & Economic & Cost & no & Brazil & & - \\
\hline An et al. (2011) & MILP & Economic & Profit & no & USA & central Texas & \\
\hline Kocoloski et al. & MILP & Economic & Cost & no & USA & Illinois & \\
\hline Kim et al. (2011a) & MILP & Economic & Profit & yes & USA & Oklahoma, Arkansas, & \\
\hline Kim et al. (2011b) & MILP & Economic & Profit & yes & USA & Oklahoma, Arkansas, & \\
\hline Papapostolou et al. & MILP & Economic & Profit & no & Greece & & - \\
\hline Zhu et al. (2011) & MILP & Economic & Profit & no & & & - \\
\hline Gan and Smith & NLP & Economic & Cost & no & & & - \\
\hline Bai et al. (2011) & MINLP & Economic & Cost & no & USA & Illinois & \\
\hline Corsano et al. (2011) & MINLP & Economic & Profit & no & & & - \\
\hline Zhang et al. (2011) & NLP & Economic & Cost & yes & USA & Michigan’s Upper & \\
\hline Singh et al. (2011) & NLP & Economic & Cost & yes & India & Bathinda district of Punjab & \\
\hline Sultana and Kumar & NLP & Economic & Cost & no & & & - \\
\hline Leboreiro and Hilaly & NLP & Economic & Cost & no & USA & Illinois & \\
\hline Yagi and Nakata & NLP & Economic & Cost & no & Japan & Miyagi, north-east & \\
\hline Ebadian et al. (2011) & Simulation & & 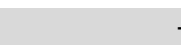 & yes & Canada & Saskatchewan & \\
\hline Elia et al. (2011) & MILP & Economic & Cost & no & USA & - & \\
\hline Marvin et al. (2012) & MILP & Economic & NPV & yes & USA & midwestern & \\
\hline Andersen et al. (2012) & MILP & Economic & NPV & no & Argentina & Chaco & \\
\hline Sultana and Kumar & NLP & Economic & Cost & yes & Canada & Alberta/Province & \\
\hline Chen and Fan (2012) & MISP & Economic & Cost & yes & USA & California & \\
\hline Avami (2012) & NLP & Economic & Cost & no & Iran & - & \\
\hline Bai et al. (2012) & Game theory & Economic & Profit & no & USA & Illinois & \\
\hline Clancy et al. (2012) & Other & Economic & NPV & no & Ireland & - & \\
\hline Keirstead et al. & MILP & Economic & Cost & no & UK & Kirklees in Yorkshire & \\
\hline Mansoornejad et al. & MILP & Economic & Profit & no & - & - & \\
\hline Zhang and Hu (2013) & MILP & Economic & Cost & no & USA & Iowa & \\
\hline Ghaffariyan et al. & LP & Economic & Cost & no & Australia & western & \\
\hline Awudu and Zhang & LP & Economic & Profit & no & USA & North Dakota & \\
\hline Osmani and Zhang & MISP & Economic & Profit & no & USA & North Dakota & \\
\hline Zhang et al. (2013) & MILP & Economic & Cost & no & USA & North Dakota & \\
\hline Ebadian et al. (2013) & MILP & Economic & Cost & no & Canada & Saskatchewan & \\
\hline Sharma et al. (2013) & LP & Economic & Cost & yes & USA & Kansas & \\
\hline Foo et al. (2013) & MILP & Economic & Cost & no & Malaysia & & - \\
\hline Avami (2013) & NLP & Economic & Cost & no & Iran & & - \\
\hline Leboreiro and Hilaly & NLP & Economic & Cost & no & - & & - \\
\hline Shabani and Sowlati & MINLP & Economic & Profit & no & Canada & & - \\
\hline Rentizelas et al. & NLP & Economic & Profitability & yes & Greece & Ampelonas & \\
\hline Wang et al. (2013) & Game theory & Economic & Profit & no & USA & Illinois & \\
\hline Gómez-González et & Heuristic & Economic & Cost & no & & & - \\
\hline Omu et al. (2013) & MILP & Economic & Cost & no & England & south & \\
\hline Lin et al. (2014) & MILP & Economic & Cost & yes & USA & Illinois & \\
\hline Roni et al. (2014) & MILP & Economic & Cost & no & USA & - & \\
\hline Xie et al. (2014) & MIP & Economic & Cost & yes & USA & California & \\
\hline Geraili et al. (2014) & LP,NLP & Economic & NPV & no & & & - \\
\hline Pantaleo et al. (2014) & MILP & Economic & Annual & no & & & - \\
\hline Grigoroudis et al. & MILP & Economic & Cost & no & & & - \\
\hline
\end{tabular}




\begin{tabular}{|c|c|c|c|c|c|c|c|}
\hline Author(s) & Design & Object & Object detail & GIS & Case & Detail & \\
\hline Paulo et al. (2014) & MILP & Economic & Net energy & no & Portugal & & - \\
\hline Marufuzzaman et al. & MILP & Economic & Cost & yes & USA & southeast region & \\
\hline Balaman and Selim & MILP & Economic & Profit & no & Turkey & - & \\
\hline Tong et al. (2014) & MILP & Economic & Cost & no & USA & Illinois & \\
\hline Bai et al. (2016) & MILP & Economic & Cost & no & USA & Illinois & \\
\hline Ahn et al. (2015) & MILP & Economic & Cost & no & Korea & - & \\
\hline Gonela et al. (2015) & MILP & Economic & Profit & no & USA & North Dakota & \\
\hline Shabani and Sowlati & MILP & Economic & Profit & no & Canada & - & \\
\hline Sharifzadeh et al. & MILP & Economic & NPV & no & England & Liverpool, london & \\
\hline Liu et al. (2015) & Design & - & & no & China & - & \\
\hline Holmgren et al. & Design & Environmental & GHG & no & Sweden & Gothenburg & \\
\hline Paulo et al. (2015) & MILP & Economic & Cost & no & Portugal & - & \\
\hline San Miguel et al. & Analyze & Environmental & Environmental & no & Spain & southern & \\
\hline Zamar et al. (2015) & Design & Uncertainty & Uncertainty & no & - & & - \\
\hline Lim and Lam (2016) & $\mathrm{LP}$ & Economic & Profit & no & Malaysia & - & \\
\hline Li and Cremaschi & MILP & Economic & NPV & no & USA & Oklahoma & \\
\hline Wu et al. (2015) & LP & Economic & Cost & no & China & & - \\
\hline Sosa et al. (2015a) & LP & Economic & Cost & yes & Ireland & & - \\
\hline Sosa et al. (2015b) & LP & Economic & Cost & yes & Ireland & & - \\
\hline Jin and Illukpitiya & Analyze & Economic & Cost & no & USA & southeast & \\
\hline Poudel et al. (2016) & MINLP & Economic & Cost & yes & USA & Mississippi and Alabama & \\
\hline Golecha and Gan & NLP & Economic & Cost & no & 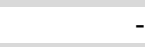 & & - \\
\hline Golecha and Gan & Game theory & Economic & Cost & no & USA & & - \\
\hline Chai and Saffron & Design & Economic & Cost & no & USA & Michigan & \\
\hline de Andrade et al. & NLP & Economic & Biomass & no & Spain & Almería & \\
\hline Zhang et al. (2016a) & MILP & Economic & Cost & yes & USA & Michigan's Lower & \\
\hline Duarte et al. (2016) & MILP & Economic & Benefit & no & Colombia & - & \\
\hline Woo et al. (2016) & MILP & Economic & Cost & no & Korea & Jeju Island & \\
\hline Zhang et al. (2016b) & MILP & Economic & Cost & yes & USA & Michigan & \\
\hline
\end{tabular}

\subsection{Multi objective studies}

Since there are a variety of purposes for modeling of biomass supply chain, multi-objective functions in this area are expanding. These papers include environmental, social, cost and etc. purpose at the same time. In this part, we classify the multi-objective papers based on the type of their objective functions.

\subsubsection{LP models}

Venema and Calamai (2003) presented a model for locating-allocating rural bioenergy in which they attempted to minimize the flow between supply chain levels. They used the p-median model in their paper. Then using their model they performed Optimization Mean Nearest Neighbour statistic and Maximization Mean Proximity Index. They also used genetic algorithm to solve their model. Ayoub et al. (2009) proposed a multi-objective MILP model for the design and evaluation of the use of biomass in the local areas network that consists of three stages: classification, problem formulation, and suggesting solution methods. The methodology is based on the biomass utilization superstructure which relates the biomass resources to system products, available processes and possible future processes as well as technology options. Zamboni et al. (2009) proposed a multi-objective MILP model for the strategic planning of their biomass supply chain. Their multi-objective model in Part 1 contains the cost minimization and in part 2 includes environmental impacts. Decisions are made regarding the production capacity of bio-diesel and plants' location by solving this model. Dal Mas et al. (2010) presented a dynamic spatially explicit MILP model to optimize the design and planning fuel demand network with financial approach in uncertain market status. They proposed two optimization criteria based on risk-seeking and risk-adverse approaches. They calculated biofuel market demand, supply chain profit, and financial risk by their model. Giarola et al. (2011) proposed a multi-period and multiechelon MILP model for environmental and financial optimization. Their paper considers corn grainand stover-based bioethanol design and strategic planning and determines biomass type selection, 
production technology, supplier allocation, site selection, capacity assignment, production planning, and transportation mode selection. Dal-Mas et al. (2011) proposed a multi-echelon MILP model to demonstrate investment risk and economic performance to decision-makers. They determined harvesting sites location, capacities, and ethanol production sites through considering the uncertainty. Akgul et al. (2012) provided a static MILP model for strategic design of a biomass supply chain network to select the location of refineries, biofuel production rate, the biomass and biofuel flow, and transport conditions in the supply chain. Their model also analyzes the merit function of biomass over other materials. Pérez-Fortes et al. (2012) provided a MILP model to determine the best pre-processing technology. Their model performs optimization through considering the capacities and locations, connections between the units of the supply chain, biomass storage periods, matter transportation flows, and electricity network.

You et al. (2012) presented planning and supply chain optimal design under the social, environmental, and economic objectives by optimizing the number of occurred local job, the life cycle GHG emission, and the annual total cost. Their model includes the main biomass features including supply seasonality and geographical diversity, biomass degradation, feedstock density, diverse conversion pathways and byproducts, infrastructure compatibility, demand distribution, regional economy, and government incentives. Their model, which is solved by e-constraint method, determines optimal network design, facility location, technology selection, capital investment, production planning, inventory control, and logistics management decisions. Fazlollahi and Maréchal (2013) proposed a multi-period multiobjective optimization model to optimize the sizes and operations in relation to the poly-generation technologies. They solved their model by a decomposition point of view. Their model is formed of EMOO (Evolutionary multi objective optimization) and MILP algorithms.

Giarola et al. (2013) proposed a MILP model for multi-period, multi-echelon supply chain. They offered a framework in decision making based on LCA regarding the strategic planning. Their economic and environmental goals are met by risk mitigation. Kanzian et al. (2013) considering roadside stock, terminals for fuel storage, shipping stations, and district heating, proposed an objective optimization model. Their model not only maximize the profit, but also minimizes $\mathrm{CO} 2$ emission. Osmani and Zhang (2014) by providing an optimization model maximized profit and minimized carbon emissions and performed modeling for dual-feedstock lignocellulosic-based bioethanol supply chain by considering the uncertainty in prices and supply and demand. The first stage determines strategic decisions while tactical decisions are made by the second stage. Santibañez-Aguilar et al. (2014) maximized the profit, minimized environmental impact, and maximized the number of jobs generated by a multi-objective multi-period MILP model that includes multiple available biomass feedstocks at harvesting sites, the availability and seasonality of biomass resources, different potential geographical locations for processing plants, economies of scale for the production technologies, demands and prices, locations of storage facilities, and a number of transportation. They solved their model by Pareto and e-constraint methods.

Cobuloglu and Büyüktahtakın (2014) proposed an optimization approach to formulate environmental and economic benefits at a farm level in second-generation feedstock supply chain. Their model that has a ten-year time horizon evaluates the environmental impacts by soil erosion prevention, sustainability of bird populations, carbon sequestration, and carbon emissions and measures economic impact by various budget, yield, and sustainability scenarios. Shabani et al. (2014) reformulated nondeterministic nonlinear available models by linear models. Their multi-period proposed model that has a one-year time horizon, has considered the supply and warehouse of forest biomass to produce electricity. Using a two-stage stochastic planning, they proposed a bi-objective model. Balaman and Selim (2014b) proposed a fuzzy model for economic and environmental modeling of energy production from animal wastes and energy crops. The multi-period model is solved by goal programming method. Balaman and Selim (2015) by providing a multi-phase model modeled the uncertain parameters involved in energy production through anaerobic digestion biomass and by providing 5 objective functions such as maximization of total annual income, minimization of investment cost, minimization 
of annual transportation cost, minimization of annual purchasing cost, and minimization of annual operational cost, they attempted to optimize their model, a model that while minimizing the costs, attempted to maximize total annual income. They used trigonometric functions with three values upper, lower and expected. De Meyer et al. (2015) modeled the supply chain in both the strategic and tactical levels. Although their model does not consider the seasonality changes associated with supply chain model, analyzes variability in biomass production, energy demand, and changes in transport distance with sensitivity analysis. They considered three scenarios. The first scenario considered the current conversion facilities. The second scenario investigated the addition of one or more anaerobic digesters. And the third one explored the optimal configuration of the conversion facilities.

Paolucci et al. (2016) proposed a two-tier point of view for the biomass pyrolysis process. In the proposed model, it is attempted to consider the economic and environmental factors. In the first layer, they attempted to make a rapid assessment of the model based on the mean of the data and in the second layer they address the details. They used a multi-objective MILP model. The effects of greenhouse gases is also considered. They used a NPV model to evaluate their plan economically. Aldana et al. (2016) proposed a multi-objective MILP model to maximize the produced energy, minimize the total costs and emit $\mathrm{CO}_{2}$. To prevent the problems of solving the multi-objective models they solved the model by solving one of the goals and putting it as the constraint. Their model considers different technologies to produce three products, such as heat, electricity, fuels and chemicals. d'Amore and Bezzo (2016) with regard to cultivation, transport, conversion, distribution, and final usage, proposed a linear model that performs economic improvement by NPV and environmental improvement by GHG emission. They considered not only the corn grain but also the stover.

\subsubsection{NLP models}

Considering several aims and modeling them synchronically with NLP models is a big challenge. Čuček et al. (2012) proposed a model based on Čuček et al. (2010) and the analysis of LCA. A two stage multi-objective MINLP model is presented in their paper. One of the goals of their model refers to the environmental conditions of footprint.

\subsubsection{Other methods}

Because of the difficulty in solving multi-objective models, many approaches have been developed including simulation and meta-heuristic algorithms to facilitate the complexity of these models. Sokhansanj et al. (2006) used a dynamic integrated biomass supply chain and logistics (IBSAL) approach to simulate collecting, storing, and transport operating. They used agricultural biomass as feedstock. Their model estimates the prices and determines the energy used and greenhouse gas emission in a variety of systems. Changes in moisture content due to weather conditions such as snow and rain are considered in their model. Gamma distribution was used to estimate the percentage of cultivated land. Kumar and Sokhansanj (2007) assessed cost, energy input, and carbon emission by an IBSAL model. Through evaluating three biomass collection systems including baling, loafing, and ensiling, they collected and stores switchgrass. They were focused on collecting and transportation costs and assessed three scenarios such as Bale, Grind, and Chop.

Ayoub et al. (2007) created gBEDS (general bioenergy decision system) model to produce energy in local and national levels by developing a DSS model. Their robust model required a lot of data extracted from GIS and earlier data related to biomass. The validity of the model was measured by simulation and optimization. Their model locates warehouses and plants at the two aforementioned levels. Ayoub et al. (2008) presented a methodology for the design and evaluation of biomass utilization networks (BUN) in the local areas. Two types of networks were developed by them. The first network is associated with the current situation and its expansion capabilities and the second network is an infrastructure that can be established. In order to solve the model that optimizes the costs, emissions, and energy consumption, a genetic algorithm is presented. The study of Mobini et al. (2011) was based 
on IBSAL and to assess delivered cost, the equilibrium moisture content, and carbon emissions in forest biomass to power plant supply chain. Their results indicate that biomass demand is not met annually. Zhang et al. (2012) proposed a simulation model that included major components of the biomass supply chain such as harvesting/processing, transportation, and storage. Their model that uses delivered feedstock cost, energy consumption, and GHG emissions as performance measures, determines optimal biofuel facility location, logistics design, inventory management, and information exchange. Perpiña et al. (2013) presented a multi-criteria evaluation using GIS to select suitable sites for establishing plants. After defining the main criterion, evaluated and weighted based on analytic hierarchies process. They classified them into three groups: environmental, economic, social. The last step of their article was to determine the sensitivity of factors and their associated weights based on variance. Mobini et al. (2013) modeled transportation using a simulation system for the wood pellet SC. The optimal sites for the plants are selected by their model. Their model that has considered the uncertainty between stages in $\mathrm{SC}$, presents the energy consumption and $\mathrm{CO}_{2}$ emissions and also the cost components of the supply chain as output. Gholamian et al. (2016) examined the different types of energies including biomass gasifier, the gas turbine, the $\mathrm{S}-\mathrm{CO}_{2}$ cycle, and the domestic water heater by applying the conservation of mass and energy. They proposed a comprehensive model including all aforementioned energies. Klein e tal. (2016) analyzed the influence of environmental factors of using biomass such as GHG emissions, without biogenic $\mathrm{CO}_{2}$; primary energy consumption, non-renewable; and particulate matter. Their study began with site preparation and ends with the plant / farm gate using the cradle to gate perspective. Table 2 summarizes multi objective studies.

Table 2

Multi objective models

\begin{tabular}{|c|c|c|c|c|c|c|}
\hline Author(s) & Design & Object(s) & Object detail(s) & GIS & Case & Detail \\
\hline Venema and & LP & Economic & Index, distance & no & & r \\
\hline Sokhansanj et al. & Simulation & Economic, technical, & Cost, energy & no & & . \\
\hline Kumar and & Simulation & Economic, technical, & Cost, energy & no & USA & midwestern \\
\hline Ayoub et al. (2007) & Simulation & Economic, & Cost, emissions, & yes & Japan & 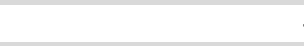 \\
\hline Ayoub et al. (2008) & other & Economic, & Cost, emissions, & no & - & . \\
\hline Ayoub et al. (2009) & MILP & Economic, & Cost, emissions, & yes & Japan & Iida city \\
\hline Zamboni et al. & MILP & Economic, & Cost, GHG emissions & yes & Italy & northern \\
\hline Dal Mas et al. & MILP & Economic & Expected profit, & no & Italy & northern \\
\hline Giarola et al. & MILP & Economic, & NPV, GHG emissions & no & Italy & northen \\
\hline Dal-Mas et al. & MILP & Economic & Profit, considering & no & Italy & northen \\
\hline Mobini et al. & Simulation & Economic, technical, & Cost, equilibrium & no & Canada & Quesnel/BritishColumbia \\
\hline Akgul et al. (2012) & MILP & Environmental, & Cost, GHG emissions & no & UK & - \\
\hline Zhang et al. (2012) & Simulation & Economic, technical, & Cost, energy & yes & USA & Lower \\
\hline Čuček et al. (2012) & MINLP & Environmental, & Profit, environmental & no & Central & - \\
\hline Pérez-Fortes et al. & MILP & Economic, & NPV, environmental & no & Ghana & Atebubu \\
\hline You et al. (2012) & MILP & Economic, & Cost, GHG emissions, & no & USA & Illinois \\
\hline Fazlollahi and & MILP & Economic, & Cost, $\mathrm{CO} 2$ emission & no & & 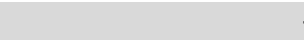 \\
\hline Giarola et al. & MILP & Economic, & NPV, GHG emissions & no & Italy & northern \\
\hline Kanzian et al. & MILP & Economic, & Profit, $\mathrm{CO} 2$ emission & yes & Austria & Burgenland, Salzburg, \\
\hline Perpiña et al. & Simulation & Environmental, & - & yes & Spain & Valencia \\
\hline Mobini et al. & Simulation & Economic, & Cost, emission, & no & Canada & British colombia \\
\hline Osmani and & MISP & Economic, & Profit, GHG emission & no & USA & Illinois (IL), Iowa (IA), \\
\hline Santibañez- & MILP & Economic, & Profit, environmental, & no & Mexico & - \\
\hline Cobuloglu and & MILP & Economic, & Total revenue, & no & USA & Kansas \\
\hline De Meyer et al. & MILP & Technical & Net energy output & yes & Belgium & Limburg \\
\hline Shabani et al. & MILP & Economic & Profit, risk of profit & no & Canada & - \\
\hline Balaman and & MILP & Economic, & Profit, bimass waste & no & Turkey & Izmir \\
\hline Balaman and & MILP & Economic & Income, cost & no & Turkey & - \\
\hline Gholamian et al. & Design & Environmental & Environmental impact & no & & 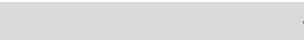 \\
\hline Klein e tal. (2016) & Analyze & Environmental & Emissions & no & Germany & Bavaria \\
\hline Aldana et al. & MILP & Economic, technical, & Cost, net energy, $\mathrm{CO} 2$ & no & Mexico & (a) \\
\hline Paolucci et al. & MINLP & Economic, & Profit, GHG emission & no & Italy & 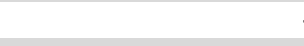 \\
\hline d'Amore and & MILP & Economic, & NPV, GHG emission & no & Italy & northern \\
\hline
\end{tabular}




\section{Classification based on case studies}

As most articles and studies include case studies, and biomass nature is intertwined with its implementation, here the papers are classified based on the areas in which the study is conducted. Fig. 3 shows the extent of the use of biomass as a renewable energy around the world. As can be seen United States has conducted the most studies in this area and Italy and Canada are in the next places.

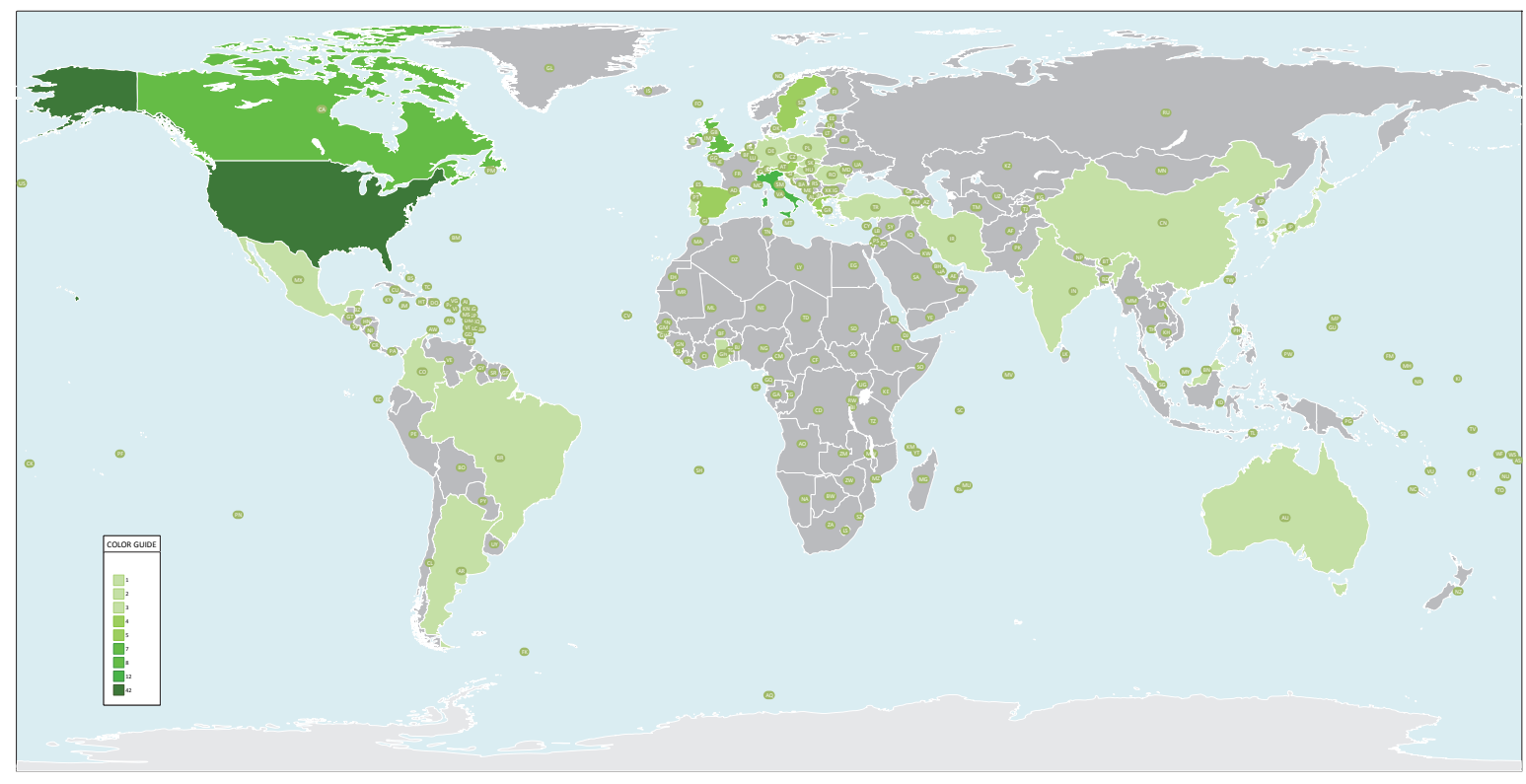

Fig. 3. Extent of using biomass

\section{Conclusion}

In this paper 140 articles were classified in two single and multi-objective categories and described in terms of their models. Related management decisions such as strategic, tactical, and operational decisions were introduced in most of the models. Research in the field of biomass supply chain network design indicated that depending on the feedstock and selecting the right technology, it is possible to achieve the intended goals such as profit, reduced environmental impact, and social aspects. On the other hand, using GIS and other techniques such as LCA and simulation can help to simplify problems and more accurate modeling.

According to the uncertainty in the field of biomass supply chain parameters, it is possible to use techniques such as stochastic programming, fuzzy programming, scenario base, sensitively analysis, and etc. that the application of which is described in the literature. Fig. 4 shows the number of singleobjective and multi-objective articles based on the type of the objective function. As it can be observed, LP includes most studies due to the simplicity in solving and modeling.

\section{Future research}

According to the presented results, since the nature of supply chain issues requires considering multiple objective functions simultaneously, and focus only on one target will reduce its practicality, the study in the field of multiple objective functions is more important and makes the problems more practical. Depending on the model type, it is possible to use solution techniques such as goal programming, goal attainment, satisfactory goals, lexicographic, and utility function. The use of these techniques is not only easy, but also leads us to an accurate solution. 
On the other hand, due to uncertainty in some parameters, as well as the impossibility of the problem by changing the input parameters, and need to provide an accurate model that is probable under all conditions, it is possible to use robust technique that is less studied in this area.

Because of the complexities in biomass supply chain problems, it is suggested to use system dynamic and decision making approaches and simplify the problems as much as possible.
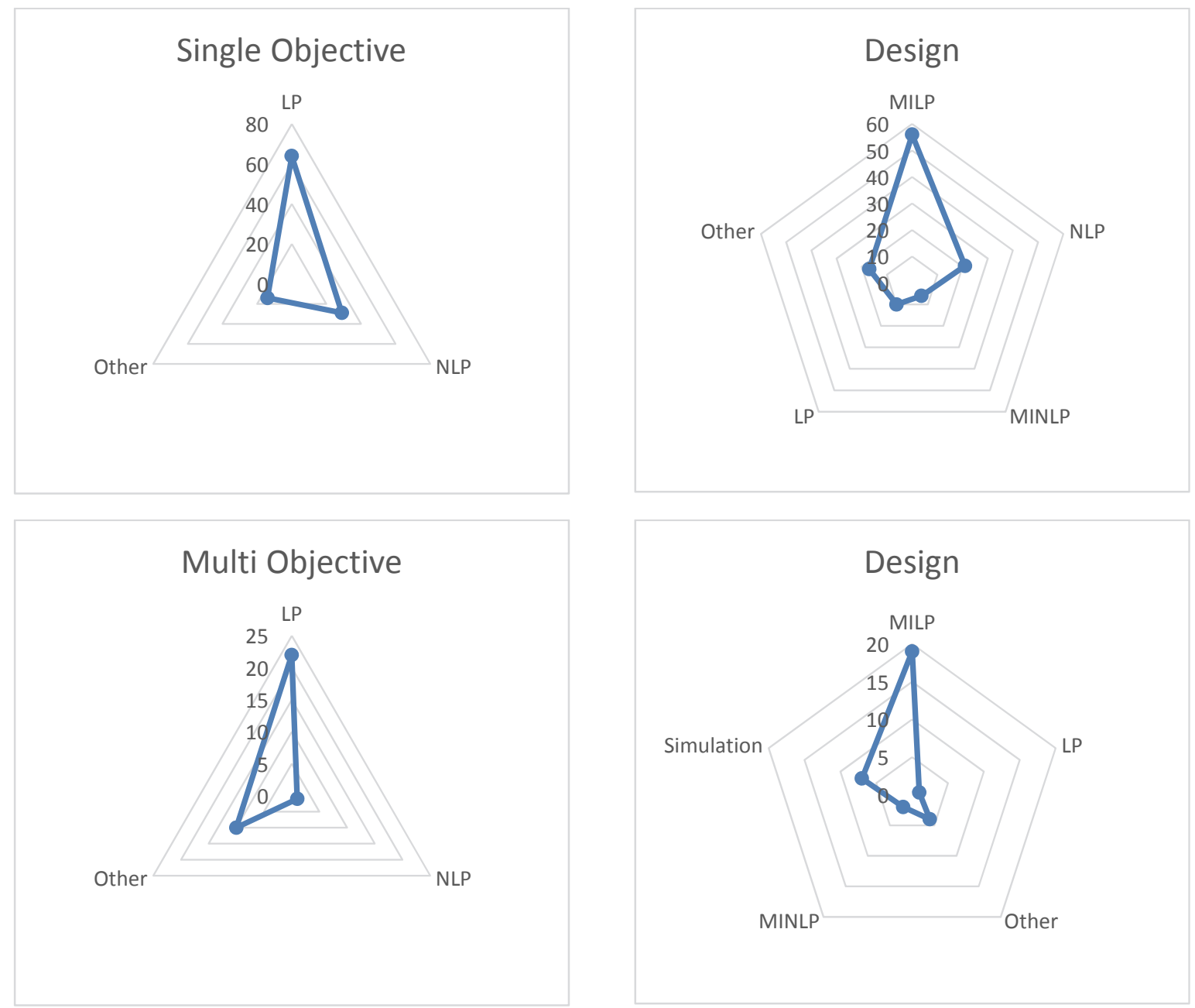

Fig. 4. Classification based on objectives

\section{Acknowledgement}

The authors would like to thank the anonymous referees for constructive comments on earlier version of this paper. 


\section{References}

Ahn, Y. C., Lee, I. B., Lee, K. H., \& Han, J. H. (2015). Strategic planning design of microalgae biomass-to-biodiesel supply chain network: Multi-period deterministic model. Applied Energy, 154, 528-542.

Akgul, O., Shah, N., \& Papageorgiou, L. G. (2012). An optimisation framework for a hybrid first/second generation bioethanol supply chain.Computers \& Chemical Engineering, 42, 101-114.

Aldana, H., Lozano, F. J., \& Acevedo, J. (2014). Evaluating the potential for producing energy from agricultural residues in México using MILP optimization. biomass and bioenergy, 67, 372-389.

An, H., Wilhelm, W. E., \& Searcy, S. W. (2011). A mathematical model to design a lignocellulosic biofuel supply chain system with a case study based on a region in Central Texas. Bioresource technology, 102(17), 7860-7870.

Andersen, F., Iturmendi, F., Espinosa, S., \& Diaz, M. S. (2012). Optimal design and planning of biodiesel supply chain with land competition.Computers \& Chemical Engineering, 47, 170-182.

Avami, A. (2012). A model for biodiesel supply chain: A case study in Iran.Renewable and Sustainable Energy Reviews, 16(6), 4196-4203.

Avami, A. (2013). Assessment of optimal biofuel supply chain planning in Iran: technical, economic, and agricultural perspectives. Renewable and Sustainable Energy Reviews, 26, 761-768.

Awudu, I., \& Zhang, J. (2013). Stochastic production planning for a biofuel supply chain under demand and price uncertainties. Applied Energy, 103, 189-196.

Ayoub, N., Elmoshi, E., Seki, H., \& Naka, Y. (2009). Evolutionary algorithms approach for integrated bioenergy supply chains optimization. Energy Conversion and Management, 50(12), 2944-2955.

Ayoub, N., Martins, R., Wang, K., Seki, H., \& Naka, Y. (2007). Two levels decision system for efficient planning and implementation of bioenergy production. Energy conversion and management, 48(3), 709-723.

Ayoub, N., Seki, H., \& Naka, Y. (2008). A methodology for designing and evaluating biomass utilization networks. Computer Aided Chemical Engineering, 25, 1053-1058.

Bai, Y., Hwang, T., Kang, S., \& Ouyang, Y. (2011). Biofuel refinery location and supply chain planning under traffic congestion. Transportation Research Part B: Methodological, 45(1), 162-175.

Bai, Y., Ouyang, Y., \& Pang, J. S. (2012). Biofuel supply chain design under competitive agricultural land use and feedstock market equilibrium. Energy Economics, 34(5), 1623-1633.

Bai, Y., Ouyang, Y., \& Pang, J. S. (2016). Enhanced models and improved solution for competitive biofuel supply chain design under land use constraints. European Journal of Operational Research, 249(1), 281-297.

Balaman, Ş. Y., \& Selim, H. (2014a). A network design model for biomass to energy supply chains with anaerobic digestion systems. Applied Energy,130, 289-304.

Balaman, S. Y., \& Selim, H. (2014b). Multiobjective optimization of biomass to energy supply chains in an uncertain environment. Computer Aided Chemical Engineering, 33, 1267-1272.

Balaman, Ş. Y., \& Selim, H. (2015). A decision model for cost effective design of biomass based green energy supply chains. Bioresource technology, 191, 97-109.

Bruglieri, M., \& Liberti, L. (2008). Optimal running and planning of a biomass-based energy production process. Energy Policy, 36(7), 2430-2438.

Chai, L., \& Saffron, C. M. (2016). Comparing pelletization and torrefaction depots: Optimization of depot capacity and biomass moisture to determine the minimum production cost. Applied Energy, 163, 387-395.

Chen, C. W., \& Fan, Y. (2012). Bioethanol supply chain system planning under supply and demand uncertainties. Transportation Research Part E: Logistics and Transportation Review, 48(1), 150164.

Clancy, D., Breen, J. P., Thorne, F., \& Wallace, M. (2012). A stochastic analysis of the decision to produce biomass crops in Ireland. Biomass and Bioenergy, 46, 353-365.

Cobuloglu, H. I., \& Büyüktahtakın, İ. E. (2014). A mixed-integer optimization model for the economic and environmental analysis of biomass production.Biomass and Bioenergy, 67, 8-23. 
Corsano, G., Vecchietti, A. R., \& Montagna, J. M. (2011). Optimal design for sustainable bioethanol supply chain considering detailed plant performance model. Computers \& Chemical Engineering, 35(8), 1384-1398.

Čuček, L., Lam, H. L., Klemeš, J. J., Varbanov, P. S., \& Kravanja, Z. (2010). Synthesis of regional networks for the supply of energy and bioproducts.Clean Technologies and Environmental Policy, 12(6), 635-645.

Čuček, L., Varbanov, P. S., Klemeš, J. J., \& Kravanja, Z. (2012). Total footprints-based multi-criteria optimisation of regional biomass energy supply chains. Energy, 44(1), 135-145.

Cundiff, J. S., Dias, N., \& Sherali, H. D. (1997). A linear programming approach for designing a herbaceous biomass delivery system. Bioresource technology, 59(1), 47-55.

d'Amore, F., \& Bezzo, F. (2016). Strategic optimisation of biomass-based energy supply chains for sustainable mobility. Computers \& Chemical Engineering, 87, 68-81.

Dal Mas, M., Giarola, S., Zamboni, A., \& Bezzo, F. (2010). Capacity planning and financial optimization of the bioethanol supply chain under price uncertainty. Computer Aided Chemical Engineering, 28, 97-102.

Dal-Mas, M., Giarola, S., Zamboni, A., \& Bezzo, F. (2011). Strategic design and investment capacity planning of the ethanol supply chain under price uncertainty. Biomass and Bioenergy, 35(5), 20592071.

de Andrade, G. A., Berenguel, M., Guzmán, J. L., Pagano, D. J., \& Acién, F. G. (2016). Optimization of biomass production in outdoor tubular photobioreactors. Journal of Process Control, 37, 58-69.

De Meyer, A., Cattrysse, D., \& Van Orshoven, J. (2015). A generic mathematical model to optimise strategic and tactical decisions in biomass-based supply chains (OPTIMASS). European Journal of Operational Research, 245(1), 247-264.

De Meyer, A., Cattrysse, D., Snoeck, M., \& Van Orshoven, J. (2012, July). Generic data model to represent the biomass-to-bioenergy supply chain logistics. In International Conference of Agricultural Engineering, CIGR-AgEng2012, Valencia, 8-12 July 2012, Papers book (Vol. 120, No. 1, pp. 1-6). Geyseco.

Demirbas, M. F., Balat, M., \& Balat, H. (2009). Potential contribution of biomass to the sustainable energy development. Energy Conversion and Management, 50(7), 1746-1760.

Duarte, A., Sarache, W., \& Costa, Y. (2016). Biofuel supply chain design from Coffee Cut Stem under environmental analysis. Energy, 100, 321-331.

Dunnett, A., Adjiman, C., \& Shah, N. (2007). Biomass to heat supply chains: applications of process optimization. Process Safety and Environmental Protection, 85(5), 419-429.

Ebadian, M., Sowlati, T., Sokhansanj, S., Stumborg, M., \& Townley-Smith, L. (2011). A new simulation model for multi-agricultural biomass logistics system in bioenergy production. Biosystems engineering, 110(3), 280-290.

Ebadian, M., Sowlati, T., Sokhansanj, S., Townley-Smith, L., \& Stumborg, M. (2013). Modeling and analysing storage systems in agricultural biomass supply chain for cellulosic ethanol production. Applied energy, 102, 840-849.

Ekşioğlu, S. D., Acharya, A., Leightley, L. E., \& Arora, S. (2009). Analyzing the design and management of biomass-to-biorefinery supply chain.Computers \& Industrial Engineering, 57(4), $1342-1352$.

Elia, J. A., Baliban, R. C., Xiao, X., \& Floudas, C. A. (2011). Optimal energy supply network determination and life cycle analysis for hybrid coal, biomass, and natural gas to liquid (CBGTL) plants using carbon-based hydrogen production. Computers \& Chemical Engineering, 35(8), 13991430.

Fazlollahi, S., \& Maréchal, F. (2013). Multi-objective, multi-period optimization of biomass conversion technologies using evolutionary algorithms and mixed integer linear programming (MILP). Applied Thermal Engineering, 50(2), 1504-1513.

Foo, D. C., Tan, R. R., Lam, H. L., Aziz, M. K. A., \& Klemeš, J. J. (2013). Robust models for the synthesis of flexible palm oil-based regional bioenergy supply chain. Energy, 55, 68-73. 
Freppaz, D., Minciardi, R., Robba, M., Rovatti, M., Sacile, R., \& Taramasso, A. (2004). Optimizing forest biomass exploitation for energy supply at a regional level. Biomass and Bioenergy, 26(1), 1525.

Frombo, F., Minciardi, R., Robba, M., \& Sacile, R. (2009). A decision support system for planning biomass-based energy production. Energy, 34(3), 362-369.

Gan, J., \& Smith, C. T. (2011). Optimal plant size and feedstock supply radius: a modeling approach to minimize bioenergy production costs.Biomass and Bioenergy, 35(8), 3350-3359.

Geraili, A., Sharma, P., \& Romagnoli, J. A. (2014). A modeling framework for design of nonlinear renewable energy systems through integrated simulation modeling and metaheuristic optimization: applications to biorefineries.Computers \& Chemical Engineering, 61, 102-117.

Ghaffariyan, M. R., Acuna, M., \& Brown, M. (2013). Analysing the effect of five operational factors on forest residue supply chain costs: A case study in Western Australia. biomass and bioenergy, 59, 486-493.

Gholamian, E., Mahmoudi, S. M. S., \& Zare, V. (2016). Proposal, exergy analysis and optimization of a new biomass-based cogeneration system.Applied Thermal Engineering, 93, 223-235.

Giarola, S., Bezzo, F., \& Shah, N. (2013). A risk management approach to the economic and environmental strategic design of ethanol supply chains.Biomass and Bioenergy, 58, 31-51.

Giarola, S., Zamboni, A., \& Bezzo, F. (2011). Spatially explicit multi-objective optimisation for design and planning of hybrid first and second generation biorefineries. Computers \& Chemical Engineering, 35(9), 1782-1797.

Gold, S. (2011). Bio-energy supply chains and stakeholders. Mitigation and Adaptation Strategies for Global Change, 16(4), 439-462.

Golecha, R., \& Gan, J. (2016a). Biomass transport cost from field to conversion facility when biomass yield density and road network vary with transport radius.Applied Energy, 164, 321-331.

Golecha, R., \& Gan, J. (2016b). Effects of corn stover year-to-year supply variability and market structure on biomass utilization and cost. Renewable and Sustainable Energy Reviews, 57, 34-44.

Gómez-González, M., López, A., \& Jurado, F. (2013). Hybrid discrete PSO and OPF approach for optimization of biomass fueled micro-scale energy system.Energy conversion and management, 65, 539-545.

Gonela, V., Zhang, J., \& Osmani, A. (2015). Stochastic optimization of sustainable industrial symbiosis based hybrid generation bioethanol supply chains. Computers \& Industrial Engineering, 87, 40-65.

Grigoroudis, E., Petridis, K., \& Arabatzis, G. (2014). RDEA: A recursive DEA based algorithm for the optimal design of biomass supply chain networks.Renewable Energy, 71, 113-122.

Gronalt, M., \& Rauch, P. (2007). Designing a regional forest fuel supply network. Biomass and Bioenergy, 31(6), 393-402.

Gunnarsson, H., Rönnqvist, M., \& Lundgren, J. T. (2004). Supply chain modelling of forest fuel. European Journal of Operational Research, 158(1), 103-123.

Paulo, H., Barbosa-Póvoa, A. P. F.D., \& Relvas, S. (2014). Energy from Lignocellulosic Biomass: Supply Chain Modeling to Maximize Net Energy Production. In 24th European Symposium on Computer Aided Process Engineering (Vol. 33, pp. 481-486).

Holmgren, K. M., Berntsson, T. S., Andersson, E., \& Rydberg, T. (2015). The influence of biomass supply chains and by-products on the greenhouse gas emissions from gasification-based bio-SNG production systems. Energy, 90, 148-162.

Huang, Y., Chen, C. W., \& Fan, Y. (2010). Multistage optimization of the supply chains of biofuels. Transportation Research Part E: Logistics and Transportation Review, 46(6), 820-830.

Izquierdo, J., Minciardi, R., Montalvo, I., Robba, M., \& Tavera, M. (2008, July). Particle Swarm Optimization for the biomass supply chain strategic planning. In Proceedings of the International Congress on Environmental Modelling and Software (pp. 1272-1280).

Jin, Y., \& Illukpitiya, P. (2016). Cost minimization of supplying biomass for ethanol biorefineries. Energy, 96, 209-214.

Kanzian, C., Holzleitner, F., Stampfer, K., \& Ashton, S. (2009). Regional energy wood logisticsoptimizing local fuel supply. Silva Fennica, 43(1), 113-128. 
Kanzian, C., Kühmaier, M., Zazgornik, J., \& Stampfer, K. (2013). Design of forest energy supply networks using multi-objective optimization. biomass and bioenergy, 58, 294-302.

Keirstead, J., Samsatli, N., Pantaleo, A. M., \& Shah, N. (2012). Evaluating biomass energy strategies for a UK eco-town with an MILP optimization model.biomass and bioenergy, 39, 306-316.

Kim, J., Realff, M. J., \& Lee, J. H. (2011b). Optimal design and global sensitivity analysis of biomass supply chain networks for biofuels under uncertainty.Computers \& Chemical Engineering, 35(9), 1738-1751.

Kim, J., Realff, M. J., Lee, J. H., Whittaker, C., \& Furtner, L. (2011a). Design of biomass processing network for biofuel production using an MILP model.Biomass and bioenergy, 35(2), 853-871.

Klein, D., Wolf, C., Schulz, C., \& Weber-Blaschke, G. (2016). Environmental impacts of various biomass supply chains for the provision of raw wood in Bavaria, Germany, with focus on climate change. Science of the Total Environment, 539, 45-60.

Kocoloski, M., Griffin, W. M., \& Matthews, H. S. (2011). Impacts of facility size and location decisions on ethanol production cost. Energy Policy, 39(1), 47-56.

Krukanont, P., \& Prasertsan, S. (2004). Geographical distribution of biomass and potential sites of rubber wood fired power plants in Southern Thailand.Biomass and bioenergy, 26(1), 47-59.

Kumar, A., \& Sokhansanj, S. (2007). Switchgrass (Panicum vigratum, L.) delivery to a biorefinery using integrated biomass supply analysis and logistics (IBSAL) model. Bioresource technology, 98(5), 1033-1044.

Lam, H. L., Klemeš, J. J., \& Kravanja, Z. (2011). Model-size reduction techniques for large-scale biomass production and supply networks. Energy,36(8), 4599-4608.

Lambert, D. K., \& Middleton, J. (2010). Logistical design of a regional herbaceous crop residue-based ethanol production complex. Biomass and Bioenergy, 34(1), 91-100.

Leão, R. R. D. C. C., Hamacher, S., \& Oliveira, F. (2011). Optimization of biodiesel supply chains based on small farmers: A case study in Brazil.Bioresource technology, 102(19), 8958-8963.

Leboreiro, J., \& Hilaly, A. K. (2011). Biomass transportation model and optimum plant size for the production of ethanol. Bioresource technology,102(3), 2712-2723.

Leboreiro, J., \& Hilaly, A. K. (2013). Analysis of supply chain, scale factor, and optimum plant capacity for the production of ethanol from corn stover. Biomass and Bioenergy, 54, 158-169.

Leduc, S., Lundgren, J., Franklin, O., \& Dotzauer, E. (2010a). Location of a biomass based methanol production plant: a dynamic problem in northern Sweden. Applied Energy, 87(1), 68-75.

Leduc, S., Schwab, D., Dotzauer, E., Schmid, E., \& Obersteiner, M. (2008). Optimal location of wood gasification plants for methanol production with heat recovery. International Journal of Energy Research, 32(12), 1080-1091.

Leduc, S., Starfelt, F., Dotzauer, E., Kindermann, G., McCallum, I., Obersteiner, M., \& Lundgren, J. (2010b). Optimal location of lignocellulosic ethanol refineries with polygeneration in Sweden. Energy, 35(6), 2709-2716.

Li, C., \& Cremaschi, S. Optimum Facility Location and Plant Scheduling for Biofuel Production. PSE2015 ESCAPE25, 274.

Liew, W. H., Hassim, M. H., \& Ng, D. K. (2014). Review of evolution, technology and sustainability assessments of biofuel production. Journal of Cleaner Production, 71, 11-29.

Lim, C. H., \& Lam, H. L. (2016). Biomass supply chain optimisation via novel biomass element life cycle analysis (BELCA). Applied Energy, 161, 733-745.

Lin, T., Rodríguez, L. F., Shastri, Y. N., Hansen, A. C., \& Ting, K. C. (2014). Integrated strategic and tactical biomass-biofuel supply chain optimization.Bioresource technology, 156, 256-266.

Liu, L., Ye, J., Zhao, Y., \& Zhao, E. (2015). The plight of the biomass power generation industry in China-A supply chain risk perspective. Renewable and Sustainable Energy Reviews, 49, 680-692.

López, P. R., Galán, S. G., Reyes, N. R., \& Jurado, F. (2008). A method for particle swarm optimization and its application in location of biomass power plants. International Journal of Green Energy, 5(3), 199-211. 
Mansoornejad, B., Pistikopoulos, E. N., \& Stuart, P. R. (2013). Scenario-based strategic supply chain design and analysis for the forest biorefinery using an operational supply chain model. International Journal of Production Economics,144(2), 618-634.

Marufuzzaman, M., Eksioglu, S. D., Li, X., \& Wang, J. (2014). Analyzing the impact of intermodalrelated risk to the design and management of biofuel supply chain. Transportation Research Part E: Logistics and Transportation Review, 69, 122-145.

Marvin, W. A., Schmidt, L. D., Benjaafar, S., Tiffany, D. G., \& Daoutidis, P. (2012). Economic optimization of a lignocellulosic biomass-to-ethanol supply chain. Chemical Engineering Science, 67(1), 68-79.

McKendry, P. (2002). Energy production from biomass (part 1): overview of biomass. Bioresource technology, 83(1), 37-46.

Mobini, M., Sowlati, T., \& Sokhansanj, S. (2011). Forest biomass supply logistics for a power plant using the discrete-event simulation approach.Applied Energy, 88(4), 1241-1250.

Mobini, M., Sowlati, T., \& Sokhansanj, S. (2013). A simulation model for the design and analysis of wood pellet supply chains. Applied energy, 111, 1239-1249.

Mohammed, M. A. A., Salmiaton, A., Azlina, W. W., Amran, M. M., \& Fakhru'l-Razi, A. (2011). Air gasification of empty fruit bunch for hydrogen-rich gas production in a fluidized-bed reactor. Energy Conversion and Management,52(2), 1555-1561.

Murphy, R., Woods, J., Black, M., \& McManus, M. (2011). Global developments in the competition for land from biofuels. Food Policy, 36, S52-S61.

Nagel, J. (2000). Determination of an economic energy supply structure based on biomass using a mixed-integer linear optimization model. Ecological Engineering, 16, 91-102.

Omu, A., Choudhary, R., \& Boies, A. (2013). Distributed energy resource system optimisation using mixed integer linear programming. Energy Policy, 61, 249-266.

Osmani, A., \& Zhang, J. (2013). Stochastic optimization of a multi-feedstock lignocellulosic-based bioethanol supply chain under multiple uncertainties.Energy, 59, 157-172.

Osmani, A., \& Zhang, J. (2014). Economic and environmental optimization of a large scale sustainable dual feedstock lignocellulosic-based bioethanol supply chain in a stochastic environment. Applied Energy, 114, 572-587.

Pantaleo, A. M., Giarola, S., Bauen, A., \& Shah, N. (2014). Integration of biomass into urban energy systems for heat and power. Part I: An MILP based spatial optimization methodology. Energy Conversion and Management, 83, 347-361.

Paolucci, N., Bezzo, F., \& Tugnoli, A. (2016). A two-tier approach to the optimization of a biomass supply chain for pyrolysis processes. Biomass and Bioenergy, 84, 87-97.

Papapostolou, C., Kondili, E., \& Kaldellis, J. K. (2011). Development and implementation of an optimisation model for biofuels supply chain. Energy,36(10), 6019-6026.

Parker, N., Tittmann, P., Hart, Q., Nelson, R., Skog, K., Schmidt, A., .. \& Jenkins, B. (2010). Development of a biorefinery optimized biofuel supply curve for the Western United States. biomass and bioenergy, 34(11), 1597-1607.

Paulo, H., Azcue, X., Barbosa-Póvoa, A. P., \& Relvas, S. (2015). Supply chain optimization of residual forestry biomass for bioenergy production: the case study of Portugal. Biomass and Bioenergy, 83, 245-256.

Pérez-Fortes, M., Laínez-Aguirre, J. M., Arranz-Piera, P., Velo, E., \& Puigjaner, L. (2012). Design of regional and sustainable bio-based networks for electricity generation using a multi-objective MILP approach. Energy, 44(1), 79-95.

Perpiña, C., Martínez-Llario, J. C., \& Pérez-Navarro, Á. (2013). Multicriteria assessment in GIS environments for siting biomass plants. Land Use Policy,31, 326-335.

Poudel, S. R., Marufuzzaman, M., \& Bian, L. (2016). Designing a reliable bio-fuel supply chain network considering link failure probabilities. Computers \& Industrial Engineering, 91, 85-99.

Reche-López, P., Ruiz-Reyes, N., Galán, S. G., \& Jurado, F. (2009). Comparison of metaheuristic techniques to determine optimal placement of biomass power plants. Energy conversion and management, 50(8), 2020-2028. 
Rentizelas, A. A., \& Tatsiopoulos, I. P. (2010). Locating a bioenergy facility using a hybrid optimization method. International Journal of Production Economics, 123(1), 196-209.

Rentizelas, A. A., Tatsiopoulos, I. P., \& Tolis, A. (2009b). An optimization model for multi-biomass tri-generation energy supply. Biomass and bioenergy, 33(2), 223-233.

Rentizelas, A. A., Tolis, A. I., \& Tatsiopoulos, I. P. (2014). Optimisation and investment analysis of two biomass-to-heat supply chain structures.Biosystems Engineering, 120, 81-91.

Rentizelas, A. A., Tolis, A. J., \& Tatsiopoulos, I. P. (2009a). Logistics issues of biomass: the storage problem and the multi-biomass supply chain. Renewable and Sustainable Energy Reviews, 13(4), 887-894.

Roni, M. S., Eksioglu, S. D., Searcy, E., \& Jha, K. (2014). A supply chain network design model for biomass co-firing in coal-fired power plants.Transportation Research Part E: Logistics and Transportation Review, 61, 115-134.

San Miguel, G., Corona, B., Ruiz, D., Landholm, D., Laina, R., Tolosana, E., ... \& Cañellas, I. (2015). Environmental, energy and economic analysis of a biomass supply chain based on a poplar short rotation coppice in Spain.Journal of Cleaner Production, 94, 93-101.

Santibañez-Aguilar, J. E., González-Campos, J. B., Ponce-Ortega, J. M., Serna-González, M., \& ElHalwagi, M. M. (2014). Optimal planning and site selection for distributed multiproduct biorefineries involving economic, environmental and social objectives. Journal of cleaner production, 65, 270-294.

Shabani, N., \& Sowlati, T. (2013). A mixed integer non-linear programming model for tactical value chain optimization of a wood biomass power plant.Applied Energy, 104, 353-361.

Shabani, N., \& Sowlati, T. (2016). A hybrid multi-stage stochastic programming-robust optimization model for maximizing the supply chain of a forest-based biomass power plant considering uncertainties. Journal of Cleaner Production, 112, 3285-3293.

Shabani, N., Sowlati, T., Ouhimmou, M., \& Rönnqvist, M. (2014). Tactical supply chain planning for a forest biomass power plant under supply uncertainty. Energy, 78, 346-355.

Sharifzadeh, M., Garcia, M. C., \& Shah, N. (2015). Supply chain network design and operation: Systematic decision-making for centralized, distributed, and mobile biofuel production using mixed integer linear programming (MILP) under uncertainty. Biomass and Bioenergy, 81, 401-414.

Sharma, B., Ingalls, R. G., Jones, C. L., Huhnke, R. L., \& Khanchi, A. (2013). Scenario optimization modeling approach for design and management of biomass-to-biorefinery supply chain system. Bioresource technology, 150, 163-171.

Singh, J., Panesar, B. S., \& Sharma, S. K. (2011). Geographical distribution of agricultural residues and optimum sites of biomass based power plant in Bathinda, Punjab. Biomass and Bioenergy, 35(10), 4455-4460.

Sokhansanj, S., Kumar, A., \& Turhollow, A. F. (2006). Development and implementation of integrated biomass supply analysis and logistics model (IBSAL). Biomass and Bioenergy, 30(10), 838-847.

Sosa, A., Acuna, M., McDonnell, K., \& Devlin, G. (2015a). Controlling moisture content and truck configurations to model and optimise biomass supply chain logistics in Ireland. Applied Energy, 137, 338-351.

Sosa, A., Acuna, M., McDonnell, K., \& Devlin, G. (2015b). Managing the moisture content of wood biomass for the optimisation of Ireland's transport supply strategy to bioenergy markets and competing industries. Energy, 86, 354-368.

Sultana, A., \& Kumar, A. (2011). Optimal configuration and combination of multiple lignocellulosic biomass feedstocks delivery to a biorefinery.Bioresource technology, 102(21), 9947-9956.

Sultana, A., \& Kumar, A. (2012). Optimal siting and size of bioenergy facilities using geographic information system. Applied Energy, 94, 192-201.

Tatsiopoulos, I. P., \& Tolis, A. J. (2003). Economic aspects of the cotton-stalk biomass logistics and comparison of supply chain methods. Biomass and Bioenergy, 24(3), 199-214.

Tembo, G., Epplin, F. M., \& Huhnke, R. L. (2003). Integrative investment appraisal of a lignocellulosic biomass-to-ethanol industry. Journal of Agricultural and Resource Economics, 611-633. 
Tong, K., Gleeson, M. J., Rong, G., \& You, F. (2014). Optimal design of advanced drop-in hydrocarbon biofuel supply chain integrating with existing petroleum refineries under uncertainty. biomass and bioenergy, 60, 108-120.

Van Dyken, S., Bakken, B. H., \& Skjelbred, H. I. (2010). Linear mixed-integer models for biomass supply chains with transport, storage and processing.Energy, 35(3), 1338-1350.

Velazquez-Marti, B., \& Fernandez-Gonzalez, E. (2010). Mathematical algorithms to locate factories to transform biomass in bioenergy focused on logistic network construction. Renewable Energy, 35(9), 2136-2142.

Venema, H. D., \& Calamai, P. H. (2003). Bioenergy systems planning using location-allocation and landscape ecology design principles. Annals of Operations Research, 123(1-4), 241-264.

Vera, D., Carabias, J., Jurado, F., \& Ruiz-Reyes, N. (2010). A Honey Bee Foraging approach for optimal location of a biomass power plant. Applied Energy, 87(7), 2119-2127.

Walla, C., \& Schneeberger, W. (2008). The optimal size for biogas plants.Biomass and bioenergy, 32(6), 551-557.

Wang, X., Ouyang, Y., Yang, H., \& Bai, Y. (2013). Optimal biofuel supply chain design under consumption mandates with renewable identification numbers.Transportation Research Part B: Methodological, 57, 158-171.

Woo, Y. B., Cho, S., Kim, J., \& Kim, B. S. (2016). Optimization-based approach for strategic design and operation of a biomass-to-hydrogen supply chain. International Journal of Hydrogen Energy, 41(12), 5405-5418.

Wu, C. B., Huang, G. H., Li, W., Xie, Y. L., \& Xu, Y. (2015). Multistage stochastic inexact chanceconstraint programming for an integrated biomass-municipal solid waste power supply management under uncertainty. Renewable and Sustainable Energy Reviews, 41, 1244-1254.

Xie, F., Huang, Y., \& Eksioglu, S. (2014). Integrating multimodal transport into cellulosic biofuel supply chain design under feedstock seasonality with a case study based on California. Bioresource technology, 152, 15-23.

Xie, Y., Zhao, K., \& Hemingway, S. (2009, October). Optimally locating biorefineries: a GIS-based mixed integer linear programming approach. In 51st Transportation Research Forum (Vol. 1, pp. 540-561).

Yagi, K., \& Nakata, T. (2011). Economic analysis on small-scale forest biomass gasification considering geographical resources distribution and technical characteristics. Biomass and bioenergy, 35(7), 2883-2892.

You, F., Tao, L., Graziano, D. J., \& Snyder, S. W. (2012). Optimal design of sustainable cellulosic biofuel supply chains: multiobjective optimization coupled with life cycle assessment and inputoutput analysis. AIChE Journal,58(4), 1157-1180.

Zamar, D. S., Gopaluni, B., Sokhansanj, S., \& Newlands, N. K. (2015). Robust Optimization of Competing Biomass Supply Chains Under Feedstock Uncertainty. IFAC-PapersOnLine, 48(8), 1222-1227.

Zamboni, A., Shah, N., \& Bezzo, F. (2009). Spatially explicit static model for the strategic design of future bioethanol production systems. 1. Cost minimization. Energy \& fuels, 23, 5121-5133.

Zhang, F., Johnson, D. M., \& Johnson, M. A. (2012). Development of a simulation model of biomass supply chain for biofuel production. Renewable Energy, 44, 380-391.

Zhang, F., Johnson, D. M., \& Sutherland, J. W. (2011). A GIS-based method for identifying the optimal location for a facility to convert forest biomass to biofuel. Biomass and Bioenergy, 35(9), 39513961.

Zhang, F., Johnson, D. M., \& Wang, J. (2016a). Integrating multimodal transport into forest-delivered biofuel supply chain design. Renewable Energy, 93, 58-67.

Zhang, F., Johnson, D., Johnson, M., Watkins, D., Froese, R., \& Wang, J. (2016b). Decision support system integrating GIS with simulation and optimisation for a biofuel supply chain. Renewable Energy, 85, 740-748.

Zhang, J., Osmani, A., Awudu, I., \& Gonela, V. (2013). An integrated optimization model for switchgrass-based bioethanol supply chain. Applied Energy, 102, 1205-1217. 
Zhang, L., \& Hu, G. (2013). Supply chain design and operational planning models for biomass to dropin fuel production. Biomass and bioenergy, 58, 238-250.

Zhu, X., Li, X., Yao, Q., \& Chen, Y. (2011). Challenges and models in supporting logistics system design for dedicated-biomass-based bioenergy industry. Bioresource technology, 102(2), 13441351.

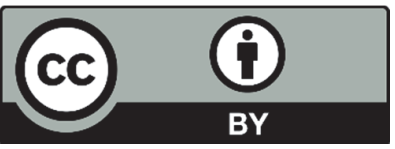

(C) 2016 by the authors; licensee Growing Science, Canada. This is an open access article distributed under the terms and conditions of the Creative Commons Attribution (CC-BY) license (http://creativecommons.org/licenses/by/4.0/). 